\title{
Social Identity and Group Contests
}

Citation for published version (APA):

Zaunbrecher, H., \& Riedl, A. (2016). Social Identity and Group Contests. Maastricht University, Graduate School of Business and Economics. GSBE Research Memoranda No. 024 https://doi.org/10.26481/umagsb.2016024

Document status and date:

Published: 01/01/2016

DOI:

10.26481/umagsb.2016024

Document Version:

Publisher's PDF, also known as Version of record

\section{Please check the document version of this publication:}

- A submitted manuscript is the version of the article upon submission and before peer-review. There can be important differences between the submitted version and the official published version of record.

People interested in the research are advised to contact the author for the final version of the publication, or visit the DOI to the publisher's website.

- The final author version and the galley proof are versions of the publication after peer review.

- The final published version features the final layout of the paper including the volume, issue and page numbers.

Link to publication

\footnotetext{
General rights rights.

- You may freely distribute the URL identifying the publication in the public portal. please follow below link for the End User Agreement:

www.umlib.nl/taverne-license

Take down policy

If you believe that this document breaches copyright please contact us at:

repository@maastrichtuniversity.nl

providing details and we will investigate your claim.
}

Copyright and moral rights for the publications made accessible in the public portal are retained by the authors and/or other copyright owners and it is a condition of accessing publications that users recognise and abide by the legal requirements associated with these

- Users may download and print one copy of any publication from the public portal for the purpose of private study or research.

- You may not further distribute the material or use it for any profit-making activity or commercial gain

If the publication is distributed under the terms of Article $25 \mathrm{fa}$ of the Dutch Copyright Act, indicated by the "Taverne" license above, 


\section{Maastricht University}

Henrik W. Zaunbrecher,

Arno Riedl

Social Identity and Group

Contests

$\mathrm{RM} / 16 / 024$

\section{GSBE}

Maastricht University School of Business and Economics

Graduate School of Business and Economics

P.O Box 616

NL- 6200 MD Maastricht

The Netherlands 


\title{
Social Identity and Group Contests
}

\author{
Henrik W. Zaunbrecher Arno Riedl ${ }^{*}$
}

May 22, 2016

\begin{abstract}
Social identity has been shown to successfully enhance cooperation and effort in cooperation and coordination games. Little is known about the causal effect of social identity on the propensity to engage in group conflict. In this paper we explore theoretically and experimentally whether social identity increases investments in group contests. We show theoretically that increased social identity with the own group implies higher investments in Tullock contests. Empirically we find that induced social identity does increase group closeness but does not increase conflict investments.
\end{abstract}

Keywords: Social identity, group, contest, experiment

JEL Classification: C92, D03, D71, D74

PsycINFO Classification: 3020

\footnotetext{
${ }^{*}$ Henrik W. Zaunbrecher: Maastricht University, Department of Economics (AE1), P.O. Box 616, 6200 MD Maastricht, The Netherlands, h.zaunbrecher@maastrichtuniversity.nl; Arno Riedl: CESifo, IZA, Netspar, and Maastricht University, Department of Economics (AE1), P.O. Box 616, 6200 MD Maastricht, The Netherlands a.riedl@maastrichtuniversity.nl
} 


\section{Introduction}

Social identity is considered an increasingly important concept for teams, organizations, and nations to align interests and create group cohesion. Sports psychology suggests that social identity is increased more in winning football teams than in losing ones (Murrell and Gaertner, 1992), that social identity increases higher order identity in Rugby teams and that it can be used to create a more prosocial environment and increase participation in exercise classes (Beauchamp and Eys, 2014). Corporations use social identity in their branding as employers as well as in advertisement campaigns. For instance, Apple's 'Get a Mac' campaign built on ingroup and outgroup differentiation to convince consumers that they want to belong to the ingroup and thus buy the companies product (Dooley, 2012). Social identity also plays an important role in managing organizations and departments. Ashforth and Mael (1989) discuss that social identity can lead to conflicts between corporate subunits in companies and to decisions that are not in the best interest of the organization as a whole. On a country level, national identity is an important ingredient for social solidarity and political mobilization but also plays an important part in many conflicts between countries Greenfeld and Chirot, 1994, Ashmore et al., 2001. ${ }^{1}$

The reported field evidence is suggestive for a causal link from social identity to conflict behavior. However, the interactions observed in the field are dynamic and thus reverse causality cannot be excluded. In this paper we use economic experiments to test whether social identity causally influences behavior in a conflict situation. Specifically, experiment participants take part in a Tullock group contest game, modeled after Tullock (1980) and Katz et al. (1990), where two groups compete for a prize by investing in a contest. The prize is fixed and thus does not increase with investment, but it does increase the probability of winning the prize. The social optimum would be to not invest at all as the prize would then be randomly allocated between groups with equal chances and both groups could keep their initial endowment. The Nash equilibrium in the contest game implies a strictly positive investment. In such a setting, experiments find significant overexpenditure compared to the Nash prediction in group contests with symmetric groups Ahn et al. 2011, Abbink et al. 2010). Abbink et al. (2012) suggest that the observed over-contribution is due to parochial altruism, a combination of ingroup love and outgroup spite. ${ }^{2}$

To test the potential effect of social identity on contest investment we implement two treatments.

In the social identity treatment participants are first exposed to a social identity task as in Chen

${ }^{1}$ Kelman (2001) describes his experiences from workshops on the Israeli-Palestinian conflict and argues that the conflict is perceived in zero-sum terms not only in disputes over territory and resources but also in terms of national identity and existence. Kelman suggests that to solve the conflict, the identities of the two nations have to evolve beyond zero-sum terms in which affirmation of the identity of one country means negation of the identity of the other nation.

${ }^{2} \mathrm{~A}$ recent overview of the literature on experimental contest games can be found in Dechenaux et al. $(2015)$. 
and Chen (2011) before they take part in a group contest where two groups of three players have to compete for the prize. In a control treatment participants also take part in the contest game but no social identity is induced. Using a social preferences model of social identity we show that in the Nash equilibrium investments are increasing with stronger social identity with the own group. In the experiment we find that inducing social identity leads to an increase in perceived closeness to the group. We do however not find an effect of induced social identity on contest investment behavior.

Next to the work on contest games cited above, our paper is also related to the recent stream of experimental work on the effect of social identity on behavior in coordination and public goods games. (Eckel and Grossman, 2005) and (Chen and Chen, 2011) find that social identity can help to increase effort levels and achieve higher welfare in public good and minimum effort games, respectively. In dictator games and two-player response games, Chen and Li (2009) have shown that social identity increases charity concerns and decreases envy towards ingroup members and increases the choice of social welfare maximizing outcomes. Charness et al. (2006) show that making group membership salient significantly increases the choice of an aggressive stance in the battle of the sexes and leads to more defections in the prisoners dilemma game. This kind of aggression towards the outgroup was also found by Bicskei et al. (2016) who use a public good game to show that individuals show higher negative reciprocity towards outgroup members than ingroup members and that anger-like emotions play a bigger role when they are matched with outgroup members. For group conflicts social psychologists such as Sherif et al. (1961), Tajfel (1970) or Stein (1976) show that external conflict with other groups increases group cohesion. These studies do however not examine whether the increased group cohesion and stronger social identity also increases the propensity to engage in conflict.

The rest of the paper is organized as follows. Section 2 presents the experimental design. Section 3 discusses the equilibrium strategies and presents hypotheses. Section 4 covers the empirical analysis. Section 5 provides a discussion of the results and concludes.

\section{Experimental setup}

In the following the social identity manipulation from Chen and Chen (2011) is adapted to a Tullock group contest game to study the effect of social identity on group conflict behavior. Two treatments were conducted, one with enhanced social identity and one control treatment. In both treatments, there are five stages. The first stage is an introduction stage in which subjects familiarize themselves with the contest game. The second stage is the group assignment stage. The third stage is the Klee 
and Kandinsky problem solving stage. The fourth stage is a group contest game that is played over multiple period. The fifth stage consists of a questionnaire. While all subjects participate in all of the stages, the second, third and fifth stage differ between treatments. ${ }^{3}$

\section{Stage 1: Introduction to Contest Game}

The group contest game used in the experiment is structured in the following way: Players receive an endowment of 100 and decide how much of the endowment they want to invest in the contest game. Endowment that is not invested is added to their account. Investments of group members of group A are labeled $i_{a}$ where $A=\{1,2,3\}$ and $a \in A$, analogously investments of group B follows. For group A the probability of winning the contest is all investments of group A over the sum of all investments by the two groups: $p_{A}\left(\sum_{a \in A} i_{a}, \sum_{b \in B} i_{b}\right)=\frac{\sum_{a \in A} i_{a}}{\sum_{a \in A} i_{a}+\sum_{b \in B} i_{b}}$. If no one invests the probability of winning is $\frac{1}{2}$. The contest prize is $\mathrm{z}$ and is equally split among all group members of the winning group. Thus if Group A is the winning group, every group member gets an individual payoff of $\frac{z}{N_{A}}$ which with $z=300$ and group sizes of 3 is 100. Each unit of investment is equivalent to a lottery ticket and at the end of the round one ticket is drawn from the investment pool of lottery tickets to decide who won the contest. Thus the more investments are made by a group, the higher the chance to win the contest. The individual payoff function can be written as:

$$
\pi_{g}\left(\sum_{a \in A} i_{a}, \sum_{b \in B} i_{b}\right)=\frac{i_{g}+\sum_{a \in A \backslash g} i_{a}}{i_{g}+\sum_{a \in A \backslash g} i_{a}+\sum_{b \in B} i_{b}} \cdot \frac{z}{N_{A}}-i_{g}
$$

Where $g$ is a member of group A and $i_{g} \in \sum_{a \in A}$. The payoff of $g$ is thus the expected individual payoff of winning the contest minus the investments made by the individual group member $g$.

To make sure that participants understand the game, several questions about randomly generated hypothetical game situations were asked. This stage was not incentivized and subjects were informed that they do not yet interact with other subjects. The first question asked how many lottery tickets the own group bought when the subject bought $x$ tickets and all other group members bought the same amount. The amount of tickets $x$ was randomized. The next three questions were based on the same $x$ and asked the subjects what the winning probability of their group, the other group and the individual expected payoff for themselves was, given that the other group invested the same total amount as their own group. The next three questions were identical to the previous three but the game situation was now such that the subject was the only one who invested and all other group members and members of the other group did not invest anything.

\footnotetext{
${ }^{3}$ The full set of instructions and screen-shots of the experiment can be found in the on-line appendix.
} 


\section{Stage 2: Group Assignment}

In the group assignment stage, all participants were randomly assigned to a group. Participants in the social identity treatment were assigned to a group color and informed about it whereas participants in the control treatment were not informed about their group assignment before the contest game. In the instructions, subjects from the social identity treatment were informed that they are matched with a group of the other color in the contest game. The groups stayed the same throughout the experiment.

\section{Stage 3: Klee and Kandinsky Task}

Each subject was given five minutes to review five pairs of paintings by Wassily Kandinsky and Paul Klee. ${ }^{4}$ The subjects also got an answer key that indicates which artist painted which painting. After the 5 minute period subjects were shown two more painting of Klee and Kandinsky. ${ }^{5}$ They had to determine for each painting if it was painted by Klee or Kandinsky. An additional five minutes are given for this task and subjects are allowed to communicate with their group via an online chat program in the social identity treatment. The control treatment is identical except for the chat function which is not made available. The decision input can only be made after the five minutes are over. Each correct answer earns ten experimental currency units. Participants are not informed about the result of this stage until the end of the experiment. ${ }^{6}$

\section{Stage 4: Group Contest}

In the contest stage, subjects play the group contest for 15 periods. After each round they are informed which group won, how much each group member of their group invested, how much the other group invested in total and what the probability of winning the contest was for their group. At the end of the last period, one of the rounds is randomly selected and paid out. Subjects get the information which round was selected, how much they earned in that round, how much they earned in the picture task and how much they will get paid out. ${ }^{7}$

\footnotetext{
${ }^{4}$ The paintings are the same as in Chen and $\mathrm{Li}(2009)$ and Chen and Chen $(2011)$ : Gebirgsbildung, 1924, by Klee; Subdued Glow, 1928, by Kandinsky; Dreamy Improvisation, 1913, by Kandinsky; Warning of the Ships, 1917, by Klee; Dry-Cool Garden, 1921, by Klee; Landscape with Red Splashes I, 1913, by Kandinsky; Gentle Ascent, 1934, by Kandinsky; A Hoffmannesque Tale, 1921, by Klee; Development in Brown, 1933, by Kandinsky; The Vase, 1938, by Klee.

${ }^{5}$ Monument in Fertile Country, 1929, by Klee; Start, 1928, by Kandinsky.

${ }^{6}$ This variant of the Klee and Kandinsky task was chosen based on findings by Chen and Li (2009) who compare group assignment based on picture preferences and random groups and chat/no chat treatments. The findings suggest that there is no significant difference between the random and preference based group assignment. However, random groups are preferable to get probabilistic equivalent groups and avoid unwanted dynamics that results from shared attributes in the preference based groups.

${ }^{7}$ Although there is some debate on which mechanism to use to pay subjects, payment of a randomly selected round was chosen because the random selection mechanism is the only incentive compatible mechanism under monotonicity as shown by Azrieli et al. (2012). Further validation of the random selection mechanism can be found in Cubitt et al. (1998) and Laury (2005) among others.
} 


\section{Stage 5: Survey}

At the end of each session, subjects have to fill in a questionnaire which contains questions about demographics, strategies used, group affiliation, prior knowledge of paintings and risk preference amongst others. The questions are explained in more detail in the results section.

The experiment was conducted in June 2015 at the BEElab at Maastricht University. After the introduction in a separate meeting room, subjects were visually and physically separated from each other. A print out of the the instructions was provided at the desk. Overall six sessions were conducted. Per session, half of the participants were allocated to the control and half were allocated to the social identity treatment. In total 126 subjects participated in 42 groups implying 21 independent observations, 10 for the control treatment and 11 for the social identity treatment. Each experiment session lasted about one hour. The experiment was conducted with the software z-tree (Fischbacher, 2007) and subjects were invited via ORSEE (Greiner, 2004). The subject pool mainly consists of students from Maastricht University. Participants were allowed to only participated in one sessions and treatment. Due to a recording error two groups contained a total of 3 subjects that had participated in an earlier session. Both groups as well as their matched counterparts are not used for the statistical analysis and discussion in the main text. The exchange rate of experimental currency units to euros was $10 \mathrm{ECU}=€ 1$. Participants earned on average $€ 14.5$. Subjects in the social identity treatment earned on average $€ 14$. 7 whereas control treatment subjects earned $€ 14.3$.

\section{$3 \quad$ Theory and Hypotheses}

Assuming standard preferences and common knowledge of rationality, the contest game has multiple equilibria at the individual player level but a unique equilibrium at the group level. In the following we shall therefore focus on the group level equilibrium. For the parameters of our experiment the Nash Equilibrium implies that $\sum_{a \in A} i_{a}=\sum_{b \in B} i_{b}=25 .^{8}$

In order to account for social identity in the model we closely follow the work of Charness and Rabin (2002), Chen and Li (2009) and Chen and Chen (2011) who use a utility function that is a weighted average of own and others' payoffs. We adopt the utility function of the form: $u_{g}(i)=\alpha \cdot \pi_{g}+(1-\alpha) \cdot \bar{\pi}_{A \backslash g}$, where $\pi_{g}$ is the payoff of player $g, \bar{\pi}_{A \backslash g}$ is the average payoff of player $g$ 's other group members and $\alpha$ is the weight on own payoffs that depends on social identity. ${ }^{9}$. Based on Chen and $\mathrm{Li}(2009)$ and Chen and Chen (2011), $\alpha$ is expected to be lower in the enhanced social

\footnotetext{
${ }^{8}$ See Appendix A for a full derivation of this result.

${ }^{9}$ We assume that the weight $\alpha$ is strictly positive and larger than 0.1 . For values below 0.1 there is no internal solution. See Appendix $\mathrm{A}$ for a discussion of this.
} 
identity treatment than in the control treatment as the subjects play with an enhanced ingroup instead of random strangers and thus put more weight on others' payoffs.

Applied to the contest game this assumption translates into the following payoff function of a player $g$ in group $A$ :

$$
\begin{aligned}
& u_{g}\left(\sum_{a \in A} i_{a}, \sum_{b \in B} i_{b}\right)=\alpha \cdot\left(\frac{\sum_{a \in A} i_{a}}{\sum_{a \in A} i_{a}+\sum_{b \in B} i_{b}} \cdot \frac{z}{N_{A}}-i_{g}\right)+ \\
& (1-\alpha) \cdot\left(\frac{1}{N_{A}-1}\right)\left(\left(N_{A}-1\right) \cdot \frac{\sum_{a \in A} i_{a}}{\sum_{a \in A} i_{a}+\sum_{b \in B} i_{b}} \cdot \frac{z}{N_{A}}-\sum_{a \in A \backslash g} i_{a}\right)
\end{aligned}
$$

It can be shown that, in equilibrium, group contributions decrease in $\alpha$, the weight put on own payoffs. ${ }^{10}$ As we associate a decrease in $\alpha$ with the enhanced social identity treatment, the first hypothesis regarding the effect of social identity on subject and group behavior in the contest game is as follows.

Hypothesis 1: The average contribution in the social identity treatment is greater than in the control treatment.

It is also expected that subjects who contribute more to the chat feel more attached to their group members, and thus should have a lower weight on own payoffs. This again would result in an increase in contributions.

Hypothesis 2: The contribution of subjects that participate more actively in the chat is higher than for subject who participate less actively in the chat.

The null hypothesis is that behavior does not differ between the treatments.

\section{Results}

We first provide descriptive statistics and analyze the group level data for which we derived a theoretical prediction. In the subsequent analysis we investigate the individual level contribution decision with additional information that we collected in a post-experiment questionnaire.

\subsection{Contributions on Group Level}

Figure 1 presents the average group contributions over time per treatment together with the standard preferences group level Nash equilibrium. Group contributions in both treatments start of at approximately 90 and are slightly higher in the social identity treatment for the first six rounds.

\footnotetext{
${ }^{10}$ See Appendix A for a full derivation of the equilibrium and a discussion of the comparative statics.
} 
Contributions are declining in both treatments after round six but the downward trend in the social identity treatment is more pronounced. In the last period, average contributions in the control treatment have decreased towards 80 whereas the average contributions in the social identity treatments have decreased below 50. Average group contributions are well above the standard

\section{Figure 1: Average Group Contribution}

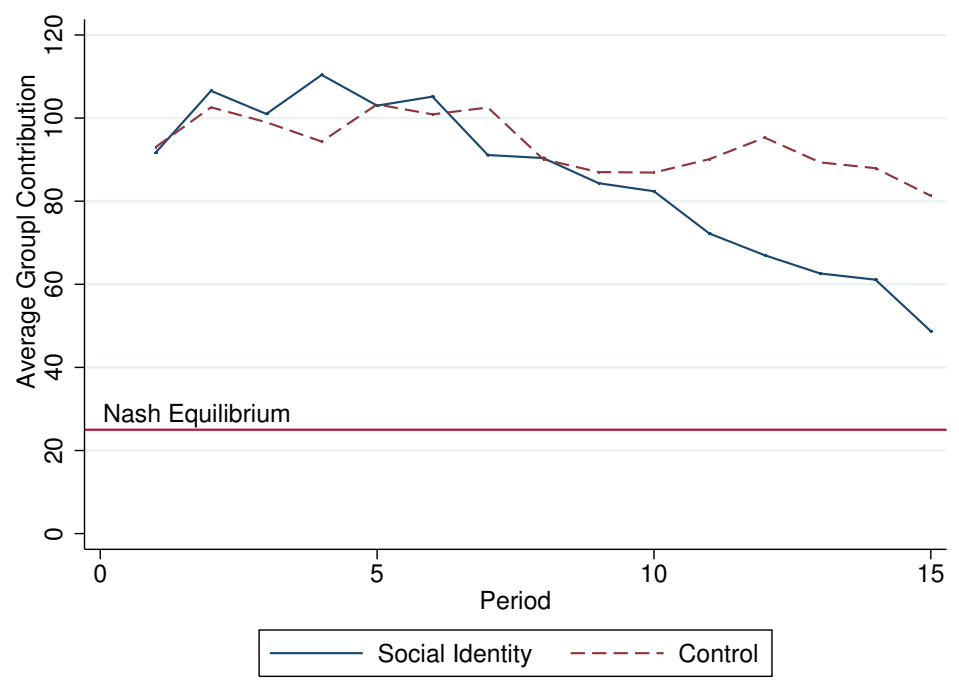

Nash equilibrium in all periods. The contribution behavior within treatments is very heterogeneous across groups but the groups in the social identity treatment seem to follow a more pronounced downward trend. ${ }^{11}$

In the following tests we use independent observations which are average group contributions per group pair. To test if the differences between treatments are significant, the Fisher-Pitman test for independent samples is used. The Fisher-Pitman test for independent samples' null hypothesis is that there is no difference in the mean of the two samples it tests. ${ }^{12}$ Table 1 presents the summary statistics for the group contributions in total and per treatment together with the Fisher-Pitman p-values. The mean group contributions in the social identity and control treatment are 85.17 and 93.58 respectively. The difference between the two treatments is relatively small compared to the standard deviations of 34.43 and 36.30 within both treatments. The difference between treatments is statistically not significant.

\footnotetext{
${ }^{11}$ Graphs for individual group behavior are provided in Appendix B

${ }^{12}$ The Fisher-Pitman tests work like the more commonly Wilcoxon rank-sum and the Mann-Whitney-U test but do not transform the data into ranks. This allows the Fisher-Pitman tests to not only consider the sign of the differences between observations but also the size of the difference. For an explanation of the method and comparison with Wilcoxon and Mann-Whitney-U see Siegel and Castellan (1988). For a more recent discussion and STATA implementation see Kaiser (2007). All hypothesis tests were also conducted with the respective Wilcoxon and Mann.Whitney-U tests as robustness check but rejections and non-rejections were identical to the Fisher-Pitman tests.
} 
We also compare contributions in the first five, the sixth to tenth and eleventh to fifteenth round as social identity could fade out over time and thus comparing overall averages might distort the effect. While means and standard deviations are similar between treatments when only the group contributions over periods one to five and six to teen are considered, this is not the case for the last periods. The mean group contribution in the social identity treatment is 62.33 whereas contributions in the control treatment are still at a high level of 88.80 when only the last five rounds are considered. The standard deviation in the control is 52.27 and higher than the 36.38 in the social identity treatment. When considering period 15 only, the mean group contribution in the social identity treatment is 48.72 and 81.30 in the control. However, none of the tests report significant differences between the treatments, as there is large heterogeneity between the groups that results in very high standard deviations. These results fail to support Hypothesis 1, that inducing social identity increases contributions.

We also analyze rent dissipation in the different treatments and time periods. By deducting the standard preferences Nash Equilibrium contribution level from the group contributions we derive a measure for how much of the resources are dissipated relative to the standard Nash Equilibrium. The Fisher-Pitman test for paired replicates is used to test if rent dissipation is significantly different from zero. Table 2 reports the rent-dissipation on group level. In line with the previous

Table 1: Group Level Contributions

\begin{tabular}{lccc}
\hline \hline $\begin{array}{l}\text { Average group contribution } \\
\text { per group pair }\end{array}$ & $\begin{array}{c}\text { Control } \\
(\mathbf{N = 1 0})\end{array}$ & $\begin{array}{c}\text { Social identity } \\
(\mathbf{N}=\mathbf{9})\end{array}$ & $\begin{array}{c}\text { Fisher-Pitman } \\
\text { p-value* }\end{array}$ \\
\hline All periods & 93.58 & 84.17 & 0.6085 \\
& $(36.30)$ & $(34.43)$ & \\
Periods 1-5 & 98.45 & 102.52 & 0.7760 \\
& $(29.75)$ & $(31.20)$ & \\
Periods 6-10 & 93.49 & 90.68 & 0.8779 \\
& $(39.93)$ & $(41.24)$ & 0.2238 \\
Periods 11-15 & 88.80 & 62.33 & \\
& $(52.27)$ & $(36.38)$ & 0.1214 \\
Period 15 & 81.30 & 48.72 & \\
\hline
\end{tabular}

Standard deviation in parentheses; * two-tailed Fisher-Pitman test for independent samples with null Hypothesis that there is no difference between the mean of the two treatments 
literature on contest games, it is found that contribution levels in both treatments over all periods are significantly higher than what the standard Nash equilibrium would predict. The mean rent dissipation over all periods, which is the mean distance between group contribution and Nash equilibrium is 60.17 in the social identity treatment and 68.58 in the control treatment. When only the last period is considered rent dissipation is 23.72 in the social identity treatment and 56.30 in the control treatment.

There is no difference between the group contributions in the social identity treatment and the Nash equilibrium when only the last round is considered. In the control treatment the test is still rejected. This suggests that contributions in the social identity treatment converge to the Nash equilibrium whereas contributions in the control treatment stay fairly above it. However, as the minimum rent dissipation in the social identity treatment is negative, thus undershooting the Nash Equilibrium, this could also be a continued downward trend towards zero.

\section{Table 2: Group Rent Dissipation}

\begin{tabular}{lccc}
\hline \hline $\begin{array}{l}\text { Average group rent dissipation } \\
\text { per group pair }\end{array}$ & Mean & Standard Deviation & $\begin{array}{c}\text { Fisher-Pitman } \\
\text { p-value* }\end{array}$ \\
\hline All periods & 64.6 & 34.70 & $<0.001$ \\
$\quad$ Control Treatment & 68.58 & 36.30 & 0.004 \\
Social identity Treatment & 60.17 & 34.43 & 0.002 \\
Period 15 & 40.87 & 45.70 & 0.001 \\
Control Treatment & 56.30 & 45.26 & 0.02 \\
Social identity Treatment & 23.72 & 42.04 & 0.13 \\
\hline
\end{tabular}

Standard deviation in parentheses; * two-tailed Fisher-Pitman test for paired replicates with null Hypothesis that rent dissipation is equal to zero.

\subsection{Individual Contribution Decision}

To analyze the individual contribution decision we run four random-effects regressions of the individual contribution with standard errors that are clustered per competing group-pair. ${ }^{13}$ The first column of Table 3 shows the result of a simple regression with period-trend, treatment dummy and an interaction term as explanatory variables and individual contributions as dependent variable. The treatment dummy is not significant which is in line with the findings from the group level

\footnotetext{
${ }^{13}$ An exploratory analysis of the effect of the controls is provided in Appendix $\mathrm{C}$ summary statistics are provided in the on-line appendix.
} 
analysis. The period-trend and the interaction term have a negative coefficient but both are not significant.

To control for personal characteristics and dynamics that develop during the experiment, we include the control questions from the post experiment questionnaire as well as lagged average contribution of the other group members and lagged average contribution of the opposing group in the following regressions. For the regression in the second column that includes observations from both treatments we also include interactions between the treatment dummy and the lagged terms to account possible differences in game dynamics between the two treatments. The results for the second regression show that controlling for personal characteristics and game dynamics does not change the significance of the negative trend or the treatment dummy. The interaction between trend and social identity treatment does become significant at a $5 \%$ level, which is in line with the observation from the group level analysis that there seems the be a negative trend in the social identity treatment that is absent in the control treatment. The lagged contribution of the own and the opposing group are significant at $1 \%$ and $5 \%$ with the lagged contribution of the other group members having a larger effect than the contribution of the opposing group. The lagged contributions that are interacted with the treatment dummy are not significant. Thus individuals seem to adjust their own contribution more based on the contribution of the other group members than on the contribution of the opponent.

For the test of the second hypothesis, two of the additional individual attributes are of special interest. One of them is the closeness to the group which is measured by a questionnaire question that asks the subjects to rate how closely they felt attached to their group on a 1 to 10 scale, where 1 is "Not close at all" and 10 is "Very close". The second variable is chat activity which is the number of chat messages that subjects sent during the social identity task. Both variables are not significant, with the interaction of the two terms being not significant as well. These results do not support hypothesis 2 that chatting increases contributions, as we would expect chatting to lead to a higher group cohesion and thus a positive effect of the interaction between closeness and chat activity on contribution.

For the third and fourth regression, the data set was split into the control and social identity treatment and each treatment was analyzed on its own. The negative period-trend is only significant in the social identity treatment, supporting the observation from the group level analysis that the contribution in the social identity treatment is decreasing stronger than the control treatment. Closeness and chat activity remain not significant. The lagged contribution of the other group members and the opponent's contribution decrease in significance in the analysis of the single treatments but the size and the sign of the coefficient stays in a similar range, suggesting that this is caused by the decrease in the number of observations. 
Table 3: Individual Contribution Decision

\begin{tabular}{|c|c|c|c|c|}
\hline Variables & $\begin{array}{l}(1) \\
\text { All }\end{array}$ & $\begin{array}{l}(2) \\
\text { All }\end{array}$ & $\begin{array}{c}(3) \\
\text { Control }\end{array}$ & $\begin{array}{c}(4) \\
\text { Social Identity }\end{array}$ \\
\hline Social Identity & $\begin{array}{c}4.685 \\
(5.340)\end{array}$ & $\begin{array}{c}5.851 \\
(5.766)\end{array}$ & & \\
\hline Period-trend & $\begin{array}{l}-0.354 \\
(0.488)\end{array}$ & $\begin{array}{c}-0.278 \\
(0.269)\end{array}$ & $\begin{array}{c}-0.281 \\
(0.283)\end{array}$ & $\begin{array}{c}-1.020^{* * *} \\
(0.244)\end{array}$ \\
\hline Social Identity*Period-trend & $\begin{array}{l}-0.936 \\
(0.549)\end{array}$ & $\begin{array}{c}-0.737^{*} \\
(0.348)\end{array}$ & & \\
\hline Lag contribution of other group members & & $\begin{array}{c}0.200^{* * *} \\
(0.0362)\end{array}$ & $\begin{array}{c}0.193^{* * *} \\
(0.0386)\end{array}$ & $\begin{array}{l}0.116^{* *} \\
(0.0364)\end{array}$ \\
\hline Social Identity*Lag contr. o. group members & & $\begin{array}{l}-0.0864 \\
(0.0502)\end{array}$ & & \\
\hline Lag contribution of opposing group & & $\begin{array}{c}0.0486^{*} \\
(0.0196)\end{array}$ & $\begin{array}{c}0.0491^{*} \\
(0.0205)\end{array}$ & $\begin{array}{c}0.0618 \\
(0.0324)\end{array}$ \\
\hline Social Identity*Lag contr. o. group & & $\begin{array}{c}0.0167 \\
(0.0383)\end{array}$ & & \\
\hline Closeness to group & & $\begin{array}{c}0.320 \\
(0.538)\end{array}$ & $\begin{array}{c}0.380 \\
(0.630)\end{array}$ & $\begin{array}{c}-0.730 \\
(0.639)\end{array}$ \\
\hline Chat activity & & $\begin{array}{c}0.202 \\
(0.515)\end{array}$ & & $\begin{array}{c}0.418 \\
(0.469)\end{array}$ \\
\hline Chat*Closeness & & $\begin{array}{l}-0.0110 \\
(0.0782)\end{array}$ & & $\begin{array}{c}-0.0285 \\
(0.111)\end{array}$ \\
\hline Constant & $\begin{array}{c}34.03^{* * *} \\
(3.829)\end{array}$ & $\begin{array}{c}14.49 * * \\
(5.524)\end{array}$ & $\begin{array}{c}11.41 \\
(8.659)\end{array}$ & $\begin{array}{c}27.92^{* * *} \\
(7.415)\end{array}$ \\
\hline Controls & No & Yes & Yes & Yes \\
\hline $\mathrm{N}$ & 1710 & 1596 & 840 & 756 \\
\hline Overall $R^{2}$ & 0.039 & 0.362 & 0.391 & 0.419 \\
\hline
\end{tabular}


As robustness check, we also run the regressions with period dummies and interactions of period dummies and the treatment variable but there is no significant difference in the results. ${ }^{14}$

\subsection{Success of Social Identity Manipulation}

As the missing significant effect of the social identity treatment on group level contributions could be the result of a failure of the social identity manipulation, it is worthwhile to take a closer look at the data from the Klee and Kandinsky task. While not a perfect measure for the success of the manipulation, a comparison of the answers that participants gave to the questionnaire question that asks subjects to rate how closely attached they felt to their group can give some insight on this. If the manipulation is indeed successful in creating a social identity, subjects in the social identity treatment are expected to feel closer attached to their groups than subjects from the control treatment. Table 4 shows the average closeness overall as well as per group. The difference in mean is nearly a whole point on the 1 to 10 scale used in the questionnaire. While the maximum average closeness is similar across treatments the minimum average closeness is 3.00 in the social identity treatment whereas it is only 1.67 in the control treatment.

A Fisher-Pitman test for independent samples on the average closeness in each group shows that closeness was rated weakly significant higher at a $10 \%$ level in the social identity treatment than in the control treatment suggesting that the social identity manipulation had some success. ${ }^{15}$

Table 4: Summary Statistics Closeness

\begin{tabular}{lccc}
\hline \hline & $\begin{array}{c}\text { Control } \\
(\mathbf{N}=\mathbf{2 0})\end{array}$ & $\begin{array}{c}\text { Social Identity } \\
\mathbf{( N = 1 8 )}\end{array}$ & $\begin{array}{c}\text { Fisher-Pitman } \\
\text { p-value* }\end{array}$ \\
\hline Average closeness to group & 4.42 & 5.26 & 0.0832 \\
$(1.63)$ & $(1.20)$ & \\
\hline Standard deviation in parentheses; * two-tailed Fisher-Pitman test for independent samples \\
with null Hypothesis that there is no difference between the mean of the two treatments.
\end{tabular}

\section{Discussion and conclusion}

In this paper, the effect of social identity on conflict is experimentally investigated using a contest game. While the effect of social identity in economic games has been studied in the context of public good and minimum effort games before, it has not been extended to games where maximum

\footnotetext{
${ }^{14}$ The alternative regressions are provided in Appendix $\mathrm{C}$

${ }^{15}$ Histograms provided in Appendix D.
} 
engagement is detrimental to social welfare. A social preference function that depends on social identity similar to the utility functions used by Chen and Li (2009) and Chen and Chen (2011) is applied to the game to derive equilibrium solutions and comparative statics results. Social identity is induced by using Chen and Chen (2011)'s variant of the Klee-Kandinsky painting task to increase group contributions in a group contest game. By letting subjects solve a task with group communication groups are made salient but this fails to enhance group contributions. Group contributions are not significantly different from the control treatment which is not in line with the theory and previous findings on the positive effect of social identity on effort and contribution in coordination and public good games. Group contributions in the social identity treatment seem to follow a negative trend that is not prevalent in the control treatment. Looking at the individual contribution decision of subjects supports the finding that contributions in the social identity treatment are decreasing at a faster rate than in the control treatment. There is no indication that chatting or closeness have an effect on individual contributions.

The reason for the negative trend in the social identity treatment is open for speculation. It could be argued that subjects have higher expectations in other group members after bonding with them in the Klee and Kandinsky task and are than more disappointed when those expectations are not met, leading to more free-riding. The theoretical model employed in this paper suggests that if beliefs are introduced and subjects believe that other members of the own group increase contributions, it would be a best response to decrease the own contributions. An increase in contributions due to a higher weight on the payoffs of other group members could than be canceled out by the belief that other group members contribute more and the aggregated effect could become negative. Furthermore, if subjects were to believe that the members of the other group are completely unselfish and are also unselfish themselves, the comparative statics suggest that equilibrium contributions would not change with changes in social identity. This highlights the need for more research of the interaction of beliefs and social identity and especially of situations in which changes in beliefs might cause an effect that is opposed to the expected effect of a change in social preferences.

The social identity manipulation that is employed in the study closely follows the design employed by Chen and $\mathrm{Li}(2009)$ and Chen and Chen (2011) who found a significant effect of identity on behavior. The results of our study resonate with some recent evidence that shows that social identity in the lab might be harder to induce than earlier papers suggested. Camerer et al. (2016) fail to replicate Chen and Chen (2011) and Guala and Filippin (2015) show widely inconsistent effects of social identity across different contexts in modified dictator games. While the fact that we find a weakly significant higher closeness in the social identity treatment is supporting evidence that the Klee and Kandinsky task is effective in enhancing social identity, we do not find that 
closeness or chatting have an effect on contributions. Some of the controls hint at a heterogeneous effect of the social identity manipulation. First, there is a large standard deviation in how helpful subjects perceived the chat and, second, there is a significant positive effect of indicating the willingness to maximize group payoff in the social identity treatment that is absent in the control treatment. This could mean that the interaction between a group has to have a certain qualitative level that is also perceived as such by the subjects to achieve significant identity effects in the lab and that the social identity manipulation has only an effect on those who were willing to maximize the group payoff anyway. The lack of a unified approach to measure social identity in the lab that is capable of quantifying the success of a social identity manipulation without drastically altering the experimental design makes it difficult to identify if our manipulation failed or if the problem lies in the structure of the game itself.

A possible explanation for the missing effect of social identity on contributions in our setting that is based on the game structure and not on the social identity manipulation is a plateau effect. As contributions in the baseline setting are already well above the standard Nash predictions and an outside threat has been found to increase in-group cooperation, social identity could be less effective in enhancing group cooperation because the setup of the contest game itself could already be a strong social identity manipulation. If there are diminishing marginal returns to social identity enhancements it would not be surprising to find no or only a very small effect of the social identity manipulation when the social identity created through the group contest is already strong. An interesting path for future research would be to follow up on this and reverse the research questions to investigate the effect that the group contest setting has on social identity, as there might be a circular relationship in which the contest induces social identity, which increases contributions and escalates the conflict which leads to an even stronger identity and a further increase in contributions. 


\section{References}

Abbink, K., Brandts, J., Herrmann, B., and Orzen, H. (2010). Intergroup conflict and intra-group punishment in an experimental contest game. The American Economic Review, 100(1):420-447.

Abbink, K., Brandts, J., Herrmann, B., and Orzen, H. (2012). Parochial altruism in inter-group conflicts. Economics Letters, 117(1):45-48.

Ahn, T., Isaac, R. M., and Salmon, T. C. (2011). Rent seeking in groups. International Journal of Industrial Organization, 29(1):116-125.

Ashforth, B. E. and Mael, F. (1989). Social identity theory and the organization. The Academy of Management Review, 14(1):pp. 20-39.

Ashmore, R. D., Jussim, L., et al. (2001). Social Identity, Intergroup Conflict, and Conflict Reduction, volume 3. Oxford University Press, USA.

Azrieli, Y., Chambers, C. P., and Healy, P. J. (2012). Incentives in experiments: A theoretical analysis. Working Paper.

Beauchamp, M. R. and Eys, M. A. (2014). Group dynamics in exercise and sport psychology, volume 2. Routledge.

Bicskei, M., Lankau, M., and Bizer, K. (2016). Negative reciprocity and its relation to anger-like emotions in identity-homogeneous and -heterogeneous groups. Journal of Economic Psychology, $54: 17-34$.

Camerer, C. F., Dreber, A., Forsell, E., Ho, T.-H., Huber, J., Johannesson, M., Kirchler, M., Almenberg, J., Altmejd, A., Chan, T., Heikensten, E., Holzmeister, F., Imai, T., Isaksson, S., Nave, G., Pfeiffer, T., Razen, M., and Wu, H. (2016). Evaluating replicability of laboratory experiments in economics. Science.

Charness, G. and Rabin, M. (2002). Understanding social preferences with simple tests. Quarterly journal of Economics, pages 817-869.

Charness, G., Rigotti, L., and Rustichini, A. (2006). Individual behavior and group membership. Available at SSRN 894685.

Chen, R. and Chen, Y. (2011). The potential of social identity for equilibrium selection. American Economic Review, 101:2562-2589. 
Chen, Y. and Li, S. X. (2009). Group identity and social preferences. American Economic Review, 99(1):431-457.

Cubitt, R. P., Starmer, C., and Sugden, R. (1998). On the validity of the random lottery incentive system. Experimental Economics, 1(2):115-131.

Dechenaux, E., Kovenock, D., and Sheremeta, R. M. (2015). A survey of experimental research on contests, all-pay auctions and tournaments. Experimental Economics, 18(4):609-669.

Dohmen, T., Falk, A., Huffman, D., Sunde, U., Schupp, J., and Wagner, G. G. (2011). Individual risk attitudes: Measurement, determinants, and behavioral consequences. Journal of the European Economic Association, 9(3):522-550.

Dooley, R. (2012). Build loyalty like apple: Define your enemy. http://www.forbes.com/sites/ rogerdooley/2012/07/17/apple-enemy/. Accessed: 2015-07-30.

Eckel, C. C. and Grossman, P. J. (2005). Managing diversity by creating team identity. Journal of Economic Behavior \& Organization, 58(3):371-392.

Fischbacher, U. (2007). z-tree: Zurich toolbox for ready-made economic experiments. Experimental economics, 10(2):171-178.

Greenfeld, L. and Chirot, D. (1994). Nationalism and aggression. Theory and society, 23(1):79-130.

Greiner, B. (2004). The online recruitment system orsee 2.0-a guide for the organization of experiments in economics. University of Cologne, Working paper series in economics, 10(23):63-104.

Guala, F. and Filippin, A. (2015). The effect of group identity on distributive choice: Social preference or heuristic? The Economic Journal.

Kaiser, J. (2007). An exact and a monte carlo proposal to the fisher-pitman permutation tests for paired replicates and for independent samples. Stata Journal, 7(3):402-412.

Katz, E., Nitzan, S., and Rosenberg, J. (1990). Rent-seeking for pure public goods. Public Choice, 65(1):49-60.

Kelman, H. C. (2001). The role of national identity in conflict resolution. Social identity, intergroup conflict, and conflict reduction, 3:187.

Konrad, K. A. (2009). Strategy and dynamics in contests. OUP Catalogue. 
Laury, S. (2005). Pay one or pay all: Random selection of one choice for payment. Andrew Young School of Policy Studies Research Paper Series, (06-13).

Murrell, A. J. and Gaertner, S. L. (1992). Cohesion and sport team effectiveness: The benefit of a common group identity. Journal of Sport \& Social Issues, 16(1):1-14.

Sherif, M., Harvey, O. J., White, B. J., Hood, W. R., Sherif, C. W., et al. (1961). Intergroup conflict and cooperation: The Robbers Cave experiment, volume 10. University Book Exchange Norman, OK.

Siegel, S. and Castellan, N. (1988). Nonparametric Statistics for the Behavioral Sciences. McGrawHill international editions. Statistics series. McGraw-Hill.

Stein, A. A. (1976). Conflict and cohesion a review of the literature. Journal of Conflict Resolution, 20(1):143-172.

Tajfel, H. (1970). Experiments in intergroup discrimination. Scientific American, 223(5):96-102.

Tullock, G. (1980). Efficient rent seeking. In Toward a theory of the rent-seeking society, chapter 10, pages 97-112. Texas A \& M University Press. 


\section{APPENDICES}

\section{A Equilibrium Strategies and Social Identity}

The following sections presents theoretical predictions and equilibrium strategies. The game is first analyzed without considering social preferences. Then an extension to incorporate social identity and comparative statics are provided.

\section{A.1 Equilibrium Strategy without social preferences}

To derive the Nash equilibrium for group contributions, the first order condition of the payoff functions of individual $g$ of group A is considered.

$$
\max _{i_{g}} \pi_{g}\left(\sum_{a \in A} i_{a}, \sum_{b \in B} i_{b}\right)=\frac{i_{g}+\sum_{a \in A \backslash g} i_{a}}{i_{g}+\sum_{a \in A \backslash g} i_{a}+\sum_{b \in B} i_{b}} \cdot \frac{z}{N_{A}}-i_{g}
$$

Taking the derivative with respect to $i_{g}$ delivers the first order condition:

$$
\frac{\partial \pi_{g}\left(\sum_{a \in A} i_{a}, \sum_{b \in B} i_{b}\right)}{\partial\left(i_{g}\right)}=0 \Rightarrow \frac{\sum_{b \in B} i_{b}}{\left(\sum_{a \in A} i_{a}+\sum_{b \in B} i_{b}\right)^{2}} \cdot \frac{z}{N_{A}}-1=0
$$

To assure that this is a maximum, the second derivative is considered:

$$
\left.\left.\frac{\partial^{2} \pi_{g}\left(\sum_{a \in A} i_{a}, \sum_{b \in B} i_{b}\right)}{\partial^{2}\left(i_{g}\right)}=\frac{-2 z \sum_{a \in A} i_{a}}{N_{A}\left(\sum_{a \in A} i_{a}+\sum_{b \in B} i_{b}\right)^{3}}<0 \quad \forall \sum_{a \in A} i_{a}, \sum_{b \in B} i_{b} \in\right] 0, N_{A} * 100\right]
$$

$N_{A}$ is strictly positive, the contributions of group A and B are both between 0 and $N_{A} * 100$, thus the function is concave and the extremum a maximum except for the case where both teams invest $0 .{ }^{16}$ It can easily be shown that $\sum_{a \in A} i_{a}+\sum_{b \in B} i_{b}=0$ cannot be a maximum as it is always optimal to at least invest the minimal positive amount possible when the other Group plays 0 as this guarantees winning the prize.

\footnotetext{
${ }^{16}$ Every individual has an endowment of 100 and group sizes are assumed to be equal thus the maximum group investment for group B is $N_{B} * 100=N_{A} * 100$
} 
The first order condition can be solved for group contributions in group A: ${ }^{17}$

$$
\sum_{a \in A} i_{a}=\sqrt{\sum_{b \in B} i_{b} \cdot \frac{z}{N_{A}}}-\sum_{b \in B} i_{b}
$$

Best response for an individual $i_{b}$ in group $B$ :

$$
\frac{\sum_{a \in A} i_{a}}{\left(\sum_{a \in A} i_{a}+\sum_{b \in B} i_{b}\right)^{2}} \cdot \frac{z}{N_{B}}-1=0
$$

Substituting equation A.1 in equation A.2 gives:

$$
\begin{aligned}
\frac{\sqrt{\sum_{b \in B} i_{b} \cdot \frac{z}{N_{A}}}-\sum_{b \in B} i_{b}}{\left(\sqrt{\sum_{b \in B} i_{b} \cdot \frac{z}{N_{A}}}-\sum_{b \in B} i_{b}+\sum_{b \in B} i_{b}\right)^{2}} & =\frac{N_{B}}{z} \\
\Leftrightarrow \sqrt{\sum_{b \in B} i_{b} \cdot \frac{z}{N_{A}}}-\sum_{b \in B} i_{b} & =\frac{N_{B}}{N_{A}} \cdot \sum_{b \in B} i_{b} \\
\Leftrightarrow \sum_{b \in B} i_{b} \cdot \frac{z}{N_{A}} & =\left(1+\frac{N_{B}}{N_{A}}\right)^{2}\left(\sum_{b \in B} i_{b}\right)^{2} \\
\Leftrightarrow \sum_{b \in B} i_{b} & =\frac{z}{N_{A} \cdot\left(1+\frac{N_{B}}{N_{A}}\right)^{2}}
\end{aligned}
$$

Substituting equation A.3 in equation A.1 gives:

$$
\begin{aligned}
\sum_{a \in A} i_{a} & =\sqrt{\frac{z}{N_{A} \cdot\left(1+\frac{N_{B}}{N_{A}}\right)^{2}} \cdot \frac{z}{N_{A}}}-\frac{z}{N_{A} \cdot\left(1+\frac{N_{B}}{N_{A}}\right)^{2}} \\
\Leftrightarrow \sum_{a \in A} i_{a} & =\frac{z}{N_{A} \cdot\left(1+\frac{N_{B}}{N_{A}}\right)}-\frac{z}{N_{A} \cdot\left(1+\frac{N_{B}}{N_{A}}\right)^{2}} \\
\Leftrightarrow \sum_{a \in A} i_{a} & =\frac{z N_{B}}{N_{A}^{2} \cdot\left(1+\frac{N_{B}}{N_{A}}\right)^{2}}
\end{aligned}
$$

This result is based on the fact that the members of each team have identical valuations and constant marginal costs of investments and does not require further symmetry assumptions Abbink et al. 2010; Konrad, 2009). Furthermore, this result does not imply a unique solution in individual

\footnotetext{
${ }^{17}$ This function actually has two solutions, but the second solution always implies a negative investment from player $\mathrm{g}$, violating the boundary conditions
} 
contributions as there exist infinitely many equilibria in individual contributions such that they sum up to the expression on the right hand side. For $N_{A}=N_{B}=3$ and $z=300$ this gives:

$$
\sum_{a \in A} i_{a}=\sum_{b \in B} i_{b}=25
$$

However this model does not account for other regarding preferences and especially social identity.

\section{A.2 Equilibrium strategies with social preferences}

The adopted utility function for player $g$ is a weighted average of own payoff and the average payoff of the other group members. ${ }^{18}$

$$
\begin{aligned}
& u_{g}\left(\sum_{a \in A} i_{a}, \sum_{b \in B} i_{b}\right)=\alpha \cdot\left(\frac{\sum_{a \in A} i_{a}}{\sum_{a \in A} i_{a}+\sum_{b \in B} i_{b}} \cdot \frac{z}{N_{A}}-i_{g}\right)+ \\
& (1-\alpha) \cdot\left(\frac{1}{N_{A}-1}\right)\left(\left(N_{A}-1\right) \cdot \frac{\sum_{a \in A} i_{a}}{\sum_{a \in A} i_{a}+\sum_{b \in B} i_{b}} \cdot \frac{z}{N_{A}}-\sum_{a \in A \backslash g} i_{a}\right)
\end{aligned}
$$

Deriving with respect to $i_{g}$ and setting to zero delivers the individual best response function: 19

$$
\begin{aligned}
\frac{\partial u_{g}\left(\sum_{a \in A} i_{a}, \sum_{b \in B} i_{b}\right)}{\partial\left(i_{g}\right)}=0 & \Rightarrow \frac{\sum_{b \in B} i_{b}}{\left(\sum_{a \in A} i_{a}+\sum_{b \in B} i_{b}\right)^{2}}=\frac{\alpha N_{A}}{z} \\
& \Leftrightarrow \sum_{a \in A} i_{a}=\sqrt{\sum_{b \in B} i_{b} \cdot \frac{z}{\alpha N_{A}}}-\sum_{b \in B} i_{b}
\end{aligned}
$$

The best response function for an individual of group $B$, where $\beta$ is the equivalent to $\alpha$ for group $B$ is:

$$
\frac{\sum_{a \in A} i_{a}}{\left(\sum_{a \in A} i_{a}+\sum_{b \in B} i_{b}\right)^{2}}=\frac{\beta N_{B}}{z}
$$

Assuming that $\alpha$ and $\beta$ are identical within the respective groups, substituting equation A.6

\footnotetext{
${ }^{18}$ Assuming symmetry within the group would reduce the formula to the individual payoff maximization problem that was discussed in the previous subsection.

${ }^{19}$ Proof of concavity/maximum is omitted as it is analogous to equation A.1 and $\alpha$ and $\beta$ are assumed to be strictly positive
} 
in equation $\mathrm{A} .7$ gives: ${ }^{20}$

$$
\sum_{b \in B} i_{b}=\frac{z}{\alpha N_{A} \cdot\left(1+\frac{\beta N_{B}}{\alpha N_{A}}\right)^{2}}
$$

Substituting equation A.8 in equation A.6 gives:

$$
\Rightarrow \sum_{a \in A} i_{a}=\frac{\beta z N_{B}}{\alpha^{2} N_{A}^{2} \cdot\left(1+\frac{\beta N_{B}}{\alpha N_{A}}\right)^{2}} .
$$

Same as in the model without social preferences, this does not imply a unique solution in individual contributions.

For the parameters used in the experiment this gives:

$$
\begin{aligned}
\sum_{b \in B} i_{b} & =\frac{100}{\alpha \cdot\left(1+\frac{\beta}{\alpha}\right)^{2}} \\
\sum_{a \in A} i_{a} & =\frac{\beta 100}{\alpha^{2} \cdot\left(1+\frac{\beta}{\alpha}\right)^{2}}
\end{aligned}
$$

However, as the endowment of each individual is fixed at 100 and all investments have to be larger than or equal to zero and not bigger than the endowment, the following must hold:

$$
\begin{aligned}
& 0 \leq \sum_{a \in A} i_{a} \leq N_{A} * 100 \\
& 0 \leq \sum_{b \in B} i_{b} \leq N_{B} * 100
\end{aligned}
$$

As $\alpha, \beta, z, N_{B}$ and $N_{A}$ are all either positive or zero, the first part of both inequalities holds trivially. With the values used in the experiment and using the equilibrium strategies the second part holds if:

$$
\beta \leq 3(\alpha+\beta)^{2}
$$

and

$$
\alpha \leq 3(\alpha+\beta)^{2}
$$

Figure A.1 shows the inequality plots for the two equations. The inequalities are only violated if either, alpha or beta, is smaller then 0.1. The lowest value for the weight on own payoffs that Chen and $\mathrm{Li}(2009)$ find is above 0.5 such that subjects seem to always put at least as much value on their own payoffs as they put on the payoff of their group members.

As values lower than 0.1 would require extreme altruistic behavior in which a player puts significantly more weight on other players' payoff than his own, we will assume that alpha and beta are at least 0.1 and not violating these inequalities.

\footnotetext{
${ }^{20}$ Steps are identical to the model without social preferences
} 


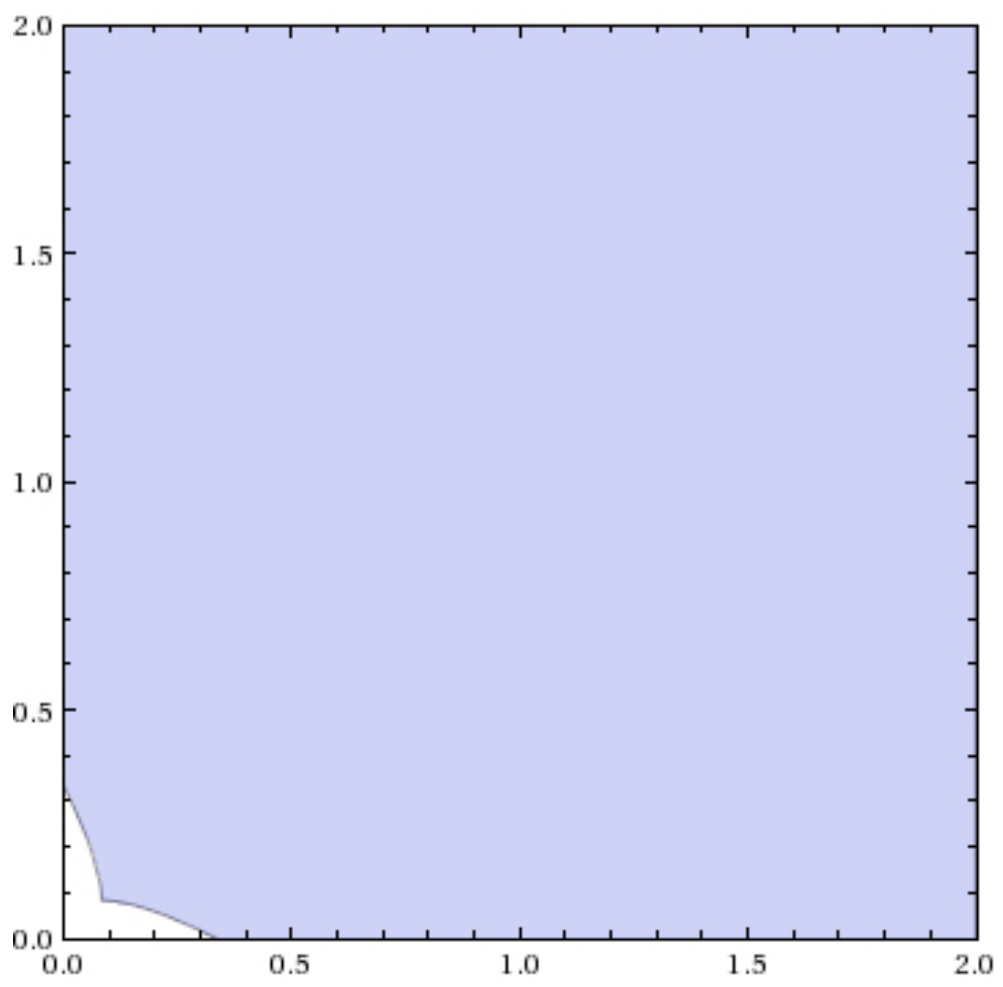

Figure A.1: Inequality Plots

(White areas indicate violation of the inequalities, $x$-axis is $\alpha$ and $y$-axis is $\beta$ )

\section{A.3 Comparative Statics}

Comparative statics with respect to the weighting parameters $\alpha$ and $\beta$ :

$$
\begin{aligned}
& \frac{\partial \sum_{a \in A} i_{a}}{\partial \alpha}=-\frac{2 \beta N_{A} N_{B} z}{\left(\alpha N_{A}+\beta N_{B}\right)^{3}}<0 \\
& \frac{\partial \sum_{a \in A} i_{a}}{\partial \beta}=\frac{N_{B} z\left(\alpha N_{A}-\beta N_{B}\right)}{\left(\alpha N_{A}+\beta N_{B}\right)^{3}} \lessgtr 0 \\
& \frac{\partial \sum_{b \in B} i_{b}}{\partial \alpha}=-\frac{N_{A} z\left(\alpha N_{A}-\beta N_{B}\right)}{\left(\alpha N_{A}+\beta N_{B}\right)^{3}} \lessgtr 0 \\
& \frac{\partial \sum_{b \in B} i_{b}}{\partial \beta}=-\frac{2 \alpha N_{A} N_{B} z}{\left(\alpha N_{A}+\beta N_{B}\right)^{3}}<0 \\
& \frac{\partial \sum_{a \in A} i_{a}}{\partial \alpha}=-\frac{N_{B} z}{\alpha^{2}\left(N_{A}+N_{B}\right)^{2}}<0 \\
& \frac{\partial \sum_{b \in B} i_{b}}{\partial \alpha}=-\frac{N_{A} z}{\alpha^{2}\left(N_{A}+N_{B}\right)^{2}}<0
\end{aligned}
$$


All of the variables are strictly positive, thus the group contribution of a group is decreasing when the weight on own payoffs $\alpha$ within the group increases. The relation with the parameter $\beta$ of the other group depends on the relation between $\alpha N_{A}$ and $\beta N_{B}$ with equilibrium contributions of group A decreasing if $\alpha N_{A}<\beta N_{B}$ and increasing if the reverse case is true. The opposite holds for group B. If both groups have the same weighting parameter, contributions are strictly decreasing in it.

Comparative statics with respect to group sizes:

$$
\begin{aligned}
& \frac{\partial \sum_{a \in A} i_{a}}{\partial N_{A}}=-\frac{2 \alpha \beta N_{B} z}{\left(\alpha N_{A}+\beta N_{B}\right)^{3}}<0 \\
& \frac{\partial \sum_{a \in A} i_{a}}{\partial N_{B}}=\frac{\beta z\left(\alpha N_{A}-\beta N_{B}\right)}{\left(\alpha N_{A}+\beta N_{B}\right)^{3}} \lessgtr 0 \\
& \frac{\partial \sum_{b \in B} i_{b}}{\partial N_{A}}=-\frac{\alpha z\left(\alpha N_{A}-\beta N_{B}\right)}{\left(\alpha N_{A}+\beta N_{B}\right)^{3}} \lessgtr 0 \\
& \frac{\partial \sum_{b \in B} i_{b}}{\partial N_{B}}=-\frac{2 \alpha \beta N_{A} z}{\left(\alpha N_{A}+\beta N_{B}\right)^{3}} \\
& \text { For } \alpha=\beta: \quad \frac{\partial \sum_{a \in A} i_{a}}{\partial N_{A}}=-\frac{2 N_{B} z}{\alpha\left(N_{A}+N_{B}\right)^{3}}<0 \\
& \frac{\partial \sum_{a \in A} i_{a}}{\partial N_{B}}=\frac{z\left(N_{A}-N_{B}\right)}{\alpha^{2}\left(N_{A}+N_{B}\right)^{3}} \lessgtr 0 \\
& \frac{\partial \sum_{b \in B} i_{b}}{\partial N_{A}}=\frac{z\left(N_{B}-N_{A}\right)}{\alpha^{2}\left(N_{A}+N_{B}\right)^{3}} \lessgtr 0 \\
& \frac{\partial \sum_{b \in B} i_{b}}{\partial N_{B}}=-\frac{2 N_{A} z}{\alpha\left(N_{A}+N_{B}\right)^{3}}<0 \\
& \operatorname{For}_{A}=N_{B} \frac{\partial \sum_{a \in A} i_{a}}{\partial N_{A}}=-\frac{2 \beta z}{N_{A}^{2}(\alpha+\beta)^{2}}<0 \\
& \partial \sum i_{b} \\
& \frac{\sum_{b \in B}}{\partial N_{A}}=-\frac{2 \alpha z}{N_{A}^{2}(\alpha+\beta)^{2}}<0 \\
& \partial \sum i_{a} \\
& \text { For } N_{A}=N_{B} \text { and } \alpha=\beta: \quad \frac{\partial \in A}{\partial N}=-\frac{z}{4 N^{2} \alpha}<0 \\
& \partial \sum i_{b} \\
& \frac{\sum_{b \in B}}{\partial N}=-\frac{z}{4 N^{2} \alpha}<0
\end{aligned}
$$

Group contributions are decreasing in own group size but the relation with the group size of the other group is again dependent on the relation between $\alpha N_{A}$ and $\beta N_{B}$. The equilibrium 
contribution of group $\mathrm{A}$ is increasing in $N_{B}$ if $\alpha N_{A}>\beta N_{B}$ and decreasing if the reverse case is true. The reverse holds for group B. If the weighting parameters are the same in both group, group contributions are still decreasing in own group size and ambiguous in others' group size. However, now it only depends on the difference in group size if the contributions are increasing or decreasing with the group size of the other group and not on the weighting parameter. If the own group is bigger than the other group then an increase in the other group results in an increase in contributions. If the own group is smaller than the other group it will decrease contributions with increases others' group size. Assuming that group sizes are equal, both group contributions are strictly decreasing in group size. In the case that group sizes as well as weighting parameters are equal, group contributions are decreasing in the weighting parameter.

Comparative Statics with respect to $\alpha$ and $\beta$ for the case when $N_{A}=N_{B}$ :

$$
\begin{array}{ll}
\text { For } N_{A}=N_{B} \quad \frac{\partial \sum_{a \in A} i_{a}}{\partial \alpha}=-\frac{2 \beta z}{N(\alpha+\beta)^{3}}<0 \\
\frac{\partial \sum_{a \in A} i_{a}}{\partial \beta}=\frac{z(\alpha-\beta)}{N(\alpha+\beta)^{3}} \lessgtr 0 \\
\frac{\partial \sum_{b \in B} i_{b}}{\partial \alpha}=\frac{z(\beta-\alpha)}{N(\alpha+\beta)^{3}} \lessgtr 0 \\
\text { For } N_{A}=N_{B} \text { and } \alpha=\beta: \quad \frac{\partial \sum_{b \in B} i_{b}}{\partial \beta}=-\frac{2 \alpha z}{N(\alpha+\beta)^{3}}<0 \\
\frac{\partial \sum_{a \in A} i_{a}}{\partial \alpha}=-\frac{z}{4 N \alpha^{2}}<0 \\
\frac{\partial \sum_{b \in B} i_{b}}{\partial \alpha}=-\frac{z}{4 N \alpha^{2}}<0
\end{array}
$$

As all parameters are strictly positive, it is clear that contributions decrease in the own weighting parameter. This also implies that an decrease in the own weighting parameter which we associate with the enhanced social identity treatment leads to an increase in contributions. The relation between the weighting parameter of the other group and own group contributions does depend on the relation between $\alpha$ and $\beta$. If $\alpha$ is smaller than $\beta$, group A's contributions decrease in $\beta$ and group B's contributions increase in $\alpha$. If $\alpha$ is bigger than $\beta$, the reverse holds true. In the case that not only group size but also weighting parameters are equal, group contributions are decreasing in the weighting parameter. 


\section{B Contributions per Group}

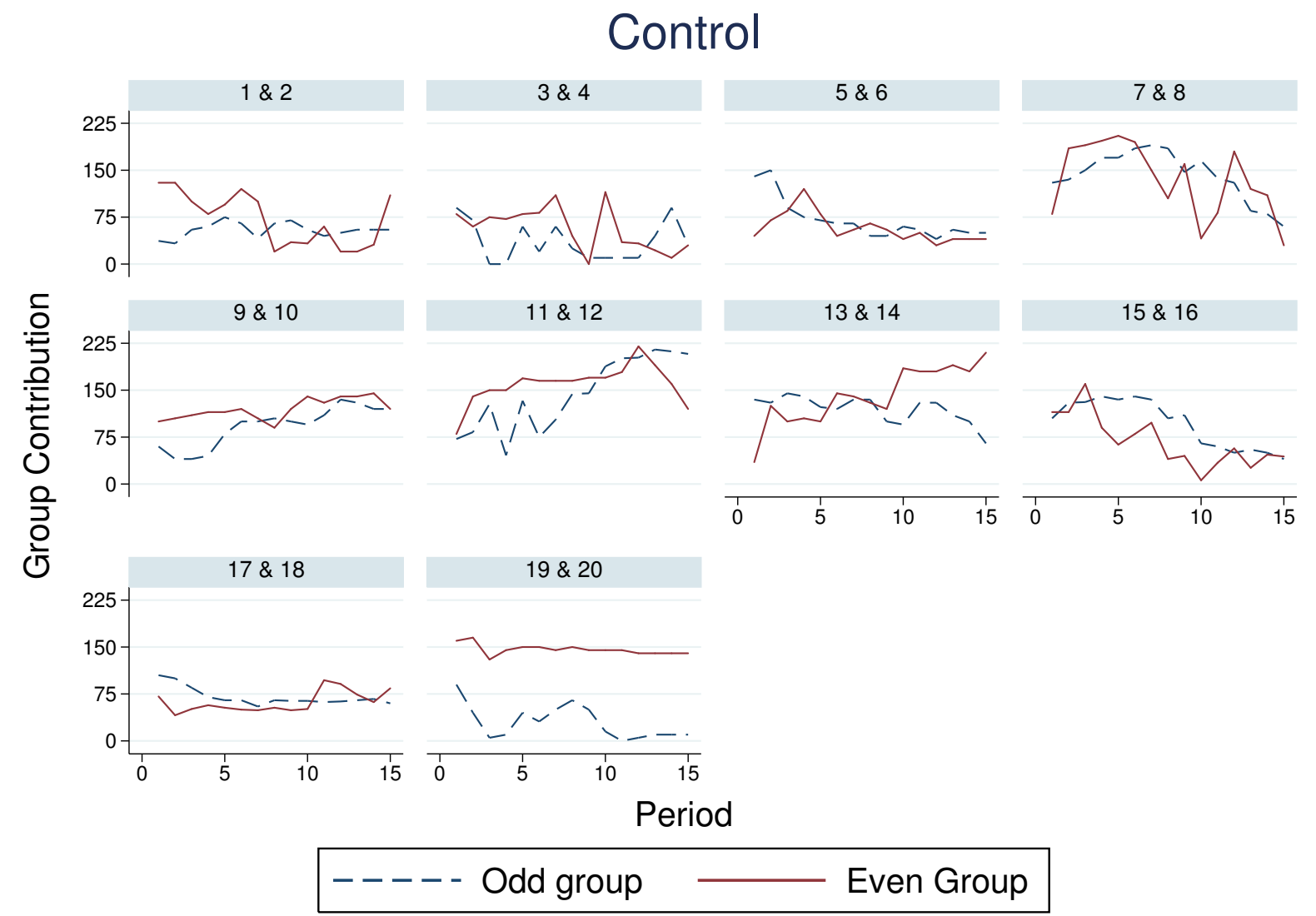

Figure B.1: Group Contributions Control Treatment 


\section{Social Identity}

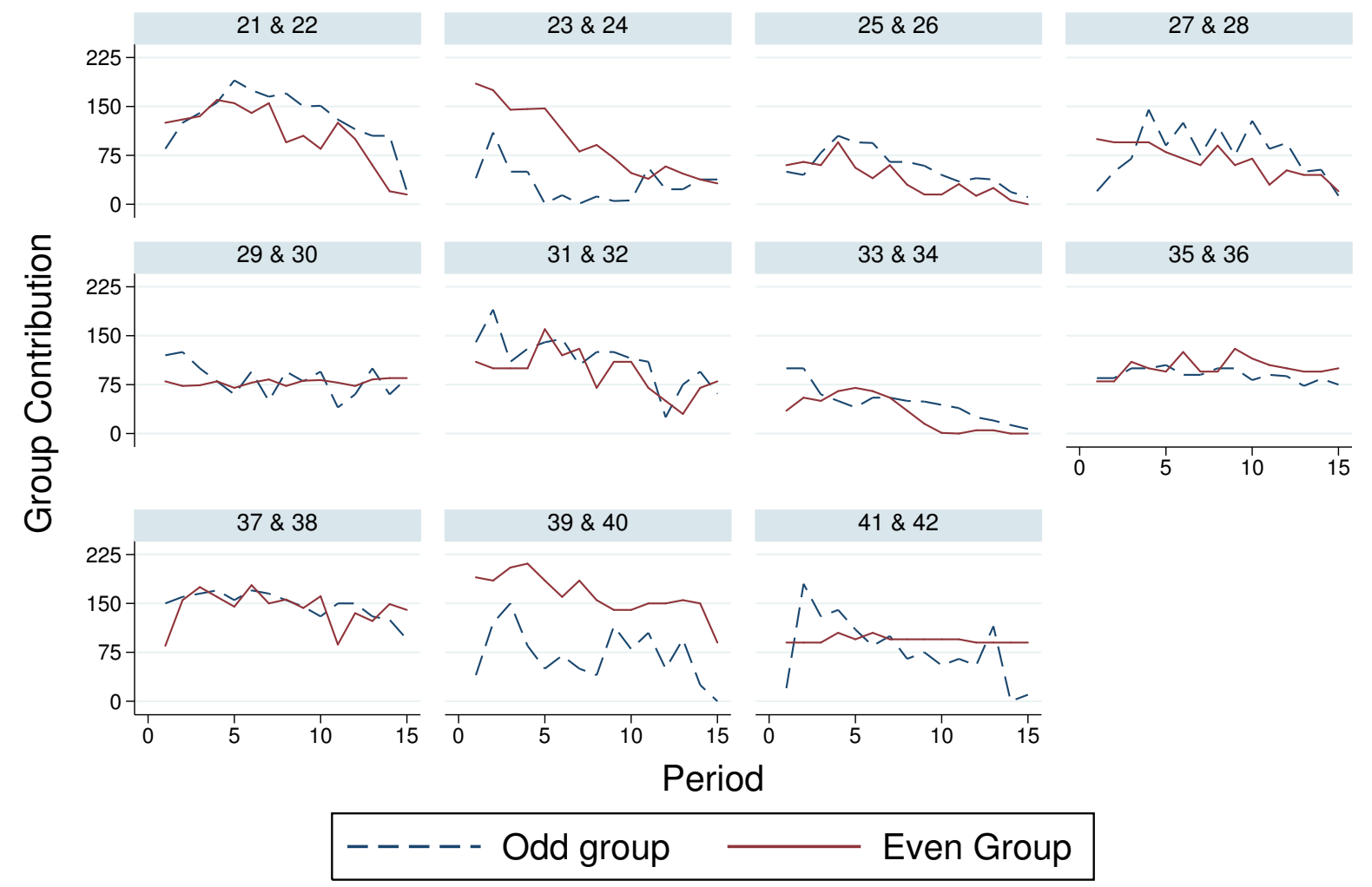

Figure B.2: Group Contributions Social Identity Treatment 


\section{Individual characteristics}

As the selection into treatments was randomized, we didn't expect and also didn't find any major differences between the treatments with regards to the descriptive statistics of the individual characteristics except for a higher number of German and Dutch students in the social identity treatment.

To measure closeness to group, subjects were asked to answer to rate how closely they felt attached to their group on a 1 to 10 scale, where 1 is "Not closely at all" and 10 is "Very closely". The mean is below 5 indicating a tendency towards not being closely attached but the standard deviation is large.

Subjects in the social identity treatment were also asked how they rated the helpfulness of the communication in the Klee and Kandinsky task on a 1 to 10 scale. The question is "On a scale from 1 to 10, please rate how much you think communicating with your group members helped solve the two extra painting questions, with 1 meaning "not much at all" and 10 meaning "very much"". The mean response indicates that subjects are slightly leaning towards finding the communication not very helpful. The distribution of answers has a fat left tail, meaning that there is a considerable amount of subjects which don't find the chat function helpful at all. The average number of messages sent per subject in the social identity treatment is 6.7 with the minimum being 1 and the maximum being 27 . Thus all subjects in the social identity treatment submitted at least one message in the group chat.

To account for previous knowledge of the pictures in the Klee and Kandinsky task, subjects were asked to rate how familiar they were with the paintings made by Klee and Kandinsky before the experiment. The scale used in the question is 1 to 10, with 1 meaning "not familiar at all" and 10 meaning "very familiar". With a mean below 3, most participants seem to be unfamiliar with the paintings used in the experiment. As the task is not intended to assess the ability to solve the picture task correctly but about communicating with the group, it is not prohibitive that some students knew the pictures before. About $26 \%$ of the subjects guessed correctly that the first picture was painted by Kandinsky and $65 \%$ of the subjects guessed correctly that the second additional picture was painted by Klee. In total the average number of correct answers was 0.92.

The English phrasing of the German Socio Economic Panel questionnaire question for general risk was used to measure risk attitude (Dohmen et al. 2011). The question is "How do you see yourself: are you generally a person who is fully prepared to take risks or do you try to avoid taking risks?" and subjects answer on a 1 to 10 scale where 1 is "not at all willing to take risks" and 10 is "very willing to take risks". The mean is very close to the middle of the scale such that the students in the sample do not seem to be particular risk averse or risk seeking. 
About $62 \%$ of the sample is female and and the average age is 21 . It is somewhat surprising that there are so many women in the sample but as it can be controlled for in the regression, this is not a major concern. The average number of siblings that subjects report is 1.6 and $80 \%$ of the students have between 0 and 2 siblings.

As subjects who are involved in team sports could show different behavior in a group contest than subjects who never participated in such group activities, the question "Have you been or are you practicing a team sports?" was included. About $65 \%$ of the sample participate or participated in team sports.

Over half of the students come from Germany or the Netherlands with other European countries accounting for another 28\%. The students from the School of Economics and Business make up $55 \%$ of the sample with only University College and Law students also participating in considerable numbers. $81 \%$ of the participants are Bachelor students. These numbers are a good representation of the subject pool, as most subjects in the pool are from the School of Economics and Business where most students are either German or Dutch and doing their bachelors degree.

To find out more about the reasoning behind the contribution decisions, subjects were also asked to indicate which strategies they used. They could chose between "I tried to earn as much money as possible", "I tried to earn as much money as possible for my group", "I tried to earn as much money as possible for both groups", "I tried to earn more than my other group members", "I tried to earn more than everybody else" and "None of the above". Subjects who chose "None of the above" were asked to give a short explanation of their contribution decisions in a free form text box. Multiple answers were possible. Of all answers given, $44 \%$ are "I tried to earn as much money as possible" and $38 \%$ are "I tried to earn as much money as possible for my group". Maximizing the payoff of both groups which is equivalent with welfare maximization was only chosen 6 times. Nearly all of the answers that indicate a desire to earn more than either the group members or the everyone else were combined with own payoff maximization or the other of the two "earn more than ..." strategies. The most common combination of strategies was "I tried to earn as much money as possible" and "I tried to earn as much money as possible for my group" which was chosen 23 times and 4 more times in combination with one or more of the other strategies.

In Table C.1 we report the coefficients for the controls that were not reported in the results section. Of all the included controls, only being an Economics or Business student, being female, having tried to maximize the group payoff and not having used any of the given strategies are significant in at least one of the three regressions. Being an economics or business students has a significant negative effect in the control group but not in the social identity group. Being female has a negative coefficient and is significant in the regression that includes both treatments but not 
in the split data sets. Indicating that one played none of the strategies that were suggested in the questionnaire has a significant negative effect in the control but none in the social identity treatment group. Indicating that one was trying to maximize the group payoff has a significant positive effect at a $1 \%$ level if both treatments are included in the regression and a positive significant effect at a $0.1 \%$ level in the social identity treatment. There is no such effect in control group. This might hint at an interaction between the treatment and those who are willing to maximize the group payoff. Given that the number of subjects that indicated to maximize the group payoff is roughly equal across the two treatments, this could mean that the social identity treatment only increases contributions for those subjects, who are already willing to maximize the group payoff and not only their own. However, comparing the contribution of those who indicated that they chose this strategy across the two treatment with a Fisher-Pitman test cannot reject the null hypothesis that the contributions are the same across treatments. ${ }^{21}$

In Table C.2 we report the result from the regressions with period dummies. The main variables of interest do not change much between the trend and the dummy models. In the first regression none of period dummies and interaction terms of period dummies and treatment variable are significant which is similar to the result with the trend dummy, where neither trend nor interaction of trend and treatment are significant. Taking into account the other controls makes the 4th and 8th dummy significant at $5 \%$ level with a negative coefficient but none of the interaction terms reaches significance which is mainly due to large standard errors. In the regressions on the separate treatment data the period dummies have large negative coefficients and are strongly significant at $1 \%$ level from period 11 onwards in the social identity treatment whereas the only significant dummy in the control treatment is period 8 which has a negative coefficient. This is in line with the finding of the result section that there is a strong negative trend in the social identity treatment but not in the control treatment.

\footnotetext{
${ }^{21}$ Fisher Pitman permutation test for independent samples. Ho: Control $=$ Social Identity : $\mathrm{p}=.86948$ (two-tailed)
} 
Table C.1: Individual Contribution Decisions Controls

\begin{tabular}{|c|c|c|c|}
\hline "Variables & All & Control & Social Identity \\
\hline \multirow[t]{2}{*}{ Risk } & 0.103 & 0.800 & -1.079 \\
\hline & $(0.692)$ & $(0.737)$ & $(1.223)$ \\
\hline \multirow[t]{2}{*}{ Female } & $-5.994^{*}$ & -6.558 & -4.745 \\
\hline & $(2.964)$ & $(4.314)$ & $(3.023)$ \\
\hline \multirow[t]{2}{*}{ Picture knowledge } & 0.135 & 0.0890 & 0.741 \\
\hline & $(0.451)$ & $(0.771)$ & $(0.942)$ \\
\hline \multirow[t]{2}{*}{ Teamsports } & 3.394 & 2.497 & 6.393 \\
\hline & $(3.055)$ & $(4.477)$ & $(5.079)$ \\
\hline \multirow[t]{2}{*}{ Siblings } & 0.479 & 2.066 & -1.670 \\
\hline & $(1.548)$ & $(2.347)$ & $(1.445)$ \\
\hline \multirow[t]{2}{*}{ Economics or Business } & -4.742 & $-6.945^{*}$ & 0.323 \\
\hline & $(2.790)$ & $(3.158)$ & $(3.316)$ \\
\hline \multirow[t]{2}{*}{ Master student } & 1.586 & 0.814 & 5.640 \\
\hline & $(3.315)$ & $(4.872)$ & $(4.215)$ \\
\hline \multirow[t]{2}{*}{ German } & -1.295 & 1.270 & -5.979 \\
\hline & $(2.700)$ & $(3.196)$ & $(3.545)$ \\
\hline \multirow[t]{2}{*}{ Dutch } & -1.425 & 1.418 & -4.340 \\
\hline & $(3.210)$ & $(4.147)$ & $(4.845)$ \\
\hline \multirow[t]{2}{*}{ S2.Maximizing group payoff } & $6.631^{* *}$ & 4.134 & $13.31^{* * *}$ \\
\hline & $(2.449)$ & $(4.090)$ & $(3.397)$ \\
\hline \multirow[t]{2}{*}{ S3.Earn more than group members } & 2.463 & 4.851 & 1.244 \\
\hline & $(5.283)$ & $(10.53)$ & $(7.095)$ \\
\hline \multirow[t]{2}{*}{ S4.Earn more than everybody else } & 3.534 & 9.081 & -6.817 \\
\hline & $(3.888)$ & $(5.193)$ & $(3.592)$ \\
\hline \multirow[t]{2}{*}{ S5.Maximize overall welfare } & -6.522 & -10.03 & -10.57 \\
\hline & $(3.950)$ & $(5.848)$ & $(7.878)$ \\
\hline \multirow[t]{2}{*}{ S6. None of the above } & -5.909 & $-11.03^{*}$ & 1.873 \\
\hline & $(5.210)$ & $(4.954)$ & $(3.669)$ \\
\hline \multirow[t]{2}{*}{ Maximizing own and group payoff } & 2.147 & 0.370 & 2.201 \\
\hline & $(2.863)$ & $(3.618)$ & $(3.912)$ \\
\hline \multirow[t]{2}{*}{ Constant } & $14.49^{* *}$ & 11.41 & $27.92^{* * *}$ \\
\hline & $(5.524)$ & $(8.659)$ & $(7.415)$ \\
\hline$N$ & 1596 & 840 & 756 \\
\hline
\end{tabular}

Standard errors clustered per group-pair in parentheses

Only controls that were not discussed in the results section are shown

${ }^{*} \mathrm{p}<0.05,{ }^{* *} \mathrm{p}<0.01,{ }^{* * *} \mathrm{p}<0.001$ 
Table C.2: Individual Contribution Decision with period Dummies

\begin{tabular}{|c|c|c|c|c|}
\hline Variables & $\begin{array}{l}\text { (1) } \\
\text { All }\end{array}$ & $\begin{array}{l}(2) \\
\text { All }\end{array}$ & $\begin{array}{c}(3) \\
\text { Control }\end{array}$ & $\begin{array}{c}(4) \\
\text { Social Identity }\end{array}$ \\
\hline Social Identity & $\begin{array}{l}-0.444 \\
(3.262)\end{array}$ & $\begin{array}{c}3.102 \\
(5.205)\end{array}$ & & \\
\hline Lag contribution of other group members & & $\begin{array}{c}0.202^{* * *} \\
(0.0365)\end{array}$ & $\begin{array}{c}0.196^{* * *} \\
(0.0390)\end{array}$ & $\begin{array}{l}0.119 * * \\
(0.0450)\end{array}$ \\
\hline Social Identity*Lag contr. o. group members & & $\begin{array}{l}-0.0865 \\
(0.0560)\end{array}$ & & \\
\hline Lag contribution of opposing group & & $\begin{array}{c}0.0505^{*} \\
(0.0204)\end{array}$ & $\begin{array}{c}0.0510^{*} \\
(0.0213)\end{array}$ & $\begin{array}{c}0.0639^{*} \\
(0.0272)\end{array}$ \\
\hline Social Identity*Lag contr. opposing group & & $\begin{array}{c}0.0170 \\
(0.0340)\end{array}$ & & \\
\hline Closeness to group & & $\begin{array}{c}0.312 \\
(0.542)\end{array}$ & $\begin{array}{c}0.375 \\
(0.636)\end{array}$ & $\begin{array}{l}-0.735 \\
(0.651)\end{array}$ \\
\hline Chat activity & & $\begin{array}{c}0.191 \\
(0.518)\end{array}$ & & $\begin{array}{c}0.406 \\
(0.487)\end{array}$ \\
\hline Chat*Closeness & & $\begin{array}{r}-0.00968 \\
(0.0787)\end{array}$ & & $\begin{array}{c}-0.0274 \\
(0.113)\end{array}$ \\
\hline Constant & $\begin{array}{c}31.00^{* * *} \\
(1.605)\end{array}$ & $\begin{array}{l}15.19^{* *} \\
(5.098)\end{array}$ & $\begin{array}{c}12.17 \\
(8.163)\end{array}$ & $\begin{array}{c}25.79^{* * *} \\
(7.715)\end{array}$ \\
\hline Controls & No & Yes & Yes & Yes \\
\hline$N$ & 1710 & 1596 & 840 & 756 \\
\hline Overall $R^{2}$ & 0.048 & 0.368 & 0.396 & 0.425 \\
\hline
\end{tabular}

Standard errors clustered per group-pair in parentheses

${ }^{*} \mathrm{p}<0.05,{ }^{* *} \mathrm{p}<0.01,{ }^{* * *} \mathrm{p}<0.001$ 
D Closeness Histograms

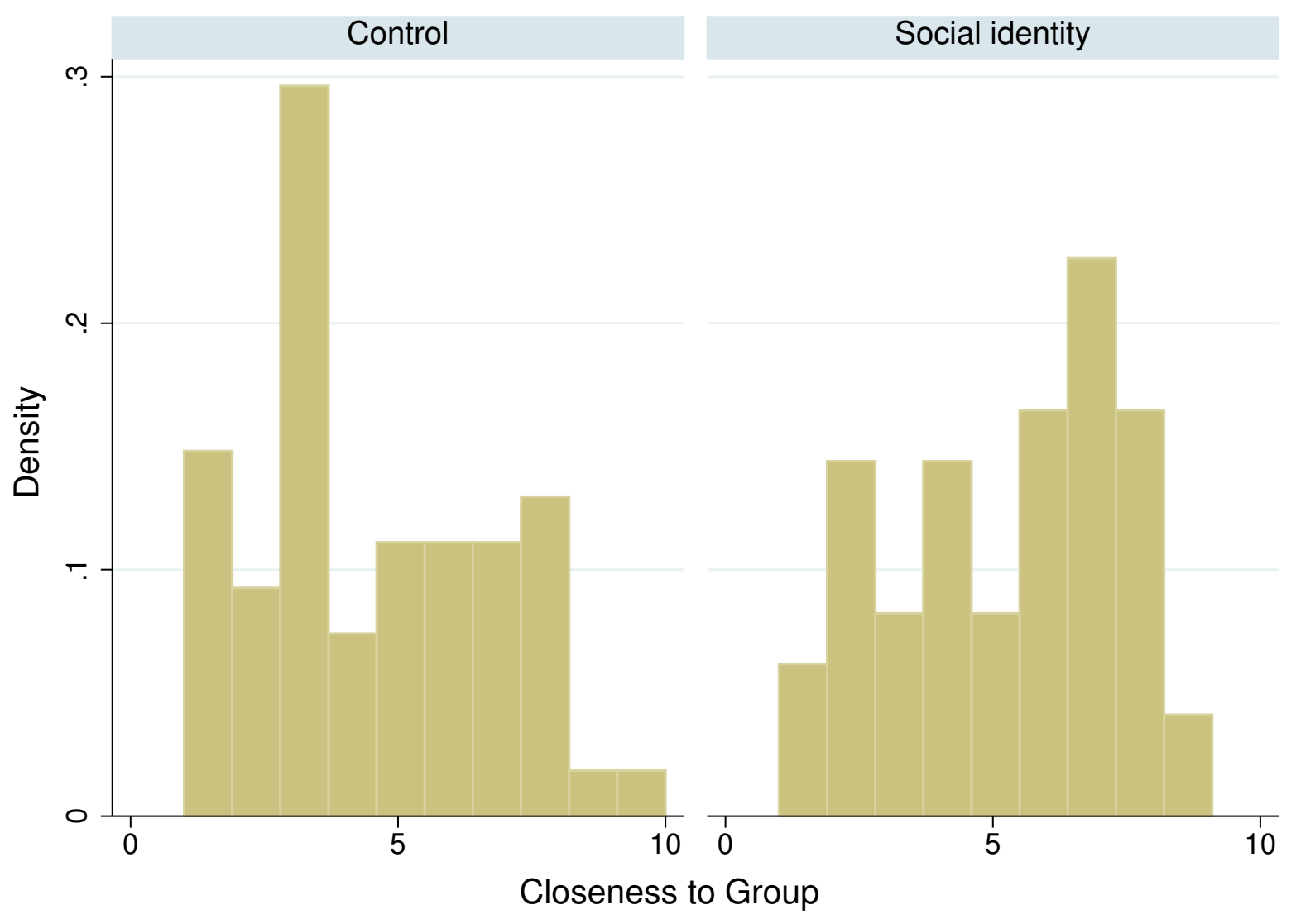

Figure D.1: Closeness to Group by Treatment 


\section{E Online Appendix}

\section{E.1 Instructions}

Control treatment:

\section{Experimental Instructions}

\section{General Instructions}

Welcome and thank you for participating in this experiment. Please read these instructions carefully. If you have any questions, please raise your hand and one of the experimenters will come to your cubicle to answer your question in private.

Talking or using mobile phones or any other electronic devices is strictly prohibited. Mobile phones and other electronic devices should be left in the waiting room or switched off. If you are found violating these rules, you will both forfeit any earnings from this experiment, and may be excluded from future experiments as well.

This is an experiment in decision-making. The amount of money you earn will depend upon the decisions you make, on the decisions other people make and random events. You will never be asked to reveal your identity to anyone during or after the course of the experiment or after. Your name will never be associated with any of your decisions. In order to keep your decisions private, do not reveal your choices to any other participant. Everyone will be paid in private.

This experiment has 2 parts and your total earnings will be the sum of your payoffs in each part.

Your earnings are given in tokens. At the end of the experiment you will be paid in cash based on the exchange rate

$€ 1=10$ tokens.

Please do not communicate with each other during the experiment unless asked to do so. If you have a question, feel free to raise your hand, and an experimenter will come to help you. 


\section{Instructions Part 1}

In Part 1 everyone will be shown 5 pairs of paintings by two artists. You will get information about the title and artist for each painting. You will have 5 minutes to study these paintings. Then you have another 5 minutes to analyse two additional paintings. After the five minutes you are asked which artist painted which of the two additional paintings. Each correct answer will bring you 10 additional tokens.

After Part 1 has finished, the second part of the experiment starts.

\section{Instructions Part 2}

Part 2 of the experiment will consist of 15 periods, and in each period you will make a decision with 2 other participants and compete for a prize with a group of 3 other participants in the following way: At the beginning of each period you will receive 100 tokens as initial endowment. Then you can use these tokens to buy lottery tickets. Any token you invest gives one lottery ticket for the group of 3. Any token you do not invest in lottery tickets will remain in your private token account. Likewise, the other two participants can buy tickets for the group and the 3 other participants can buy tickets for their group in exactly the same way.

As soon as everybody has chosen how many tickets to buy, a lottery will determine whether your group or the other group wins a prize of 300 tokens. All bought tickets are put in a "virtual" urn. One of the bought tickets will be randomly drawn as the winning ticket. Each ticket has the same chance to be drawn. Hence, the more tickets your group buys, the higher is your group's chance of winning the prize.

Examples: If your group and the other group buy the same amount of tickets then the chance of winning the prize is 50:50. This is also the case if none of the groups buy any tickets. If your group buys three times as many tickets as the other group, then also your group's chance is three times as high as that of the other group. If only one of the groups buys tickets then this group wins the prize with certainty.

After the winning group is determined the prize of 300 tokens is equally shared between the members of the winning group and added to the private token accounts. As your group consists of 3 members, everyone in the winning group gets 100 tokens). 
Earnings of a member of the winning group: 100 - bought lottery tickets +100

Earnings of a member of the losing group: 100 - bought lottery tickets

At the end of part 2 one of the 15 periods is randomly selected as the period that is paid out. You will receive information on how much you earned in each part of the experiment and which period was selected for the payoff in part 2 .

At the end of the experiment you are asked to fill out a questionnaire.

The experiment starts with a trial period in which you will be asked to fill in some questions in order to check your understanding of the experiment and to give you the opportunity to get acquainted with the setup. Tokens earned in this trial period will not be paid off.

\section{Social Identity:}

\section{Experimental Instructions}

\section{General Instructions}

Welcome and thank you for participating in this experiment. Please read these instructions carefully. If you have any questions, please raise your hand and one of the experimenters will come to your cubicle to answer your question in private.

Talking or using mobile phones or any other electronic devices is strictly prohibited. Mobile phones and other electronic devices should be left in the waiting room or switched off. If you are found violating these rules, you will both forfeit any earnings from this experiment, and may be excluded from future experiments as well.

This is an experiment in decision-making. The amount of money you earn will depend upon the decisions you make, on the decisions other people make and random events. You will never be asked to reveal your identity to anyone during or after the course of the experiment or after. Your name will never be associated with any of your decisions. In order to keep your decisions private, do not reveal your choices to any other participant. Everyone will be paid in private. 
This experiment has 2 parts and your total earnings will be the sum of your payoffs in each part.

Your earnings are given in tokens. At the end of the experiment you will be paid in cash based on the exchange rate

$€ 1=10$ tokens.

Please do not communicate with each other during the experiment unless asked to do so. If you have a question, feel free to raise your hand, and an experimenter will come to help you.

You are a member of either the Blue or the Yellow group. There are 3 people in each group. Your group assignment will remain the same throughout the experiment. That is, if you were assigned to the Blue group, you will be in the Blue group for the rest of the experiment, and if you were assigned to the Yellow group, you will be in the Yellow group for the rest of the experiment.

\section{Instructions Part 1}

In Part 1 everyone will be shown 5 pairs of paintings by two artists. You will get information about the title and artist for each painting. You will have 5 minutes to study these paintings. Then you have another 5 minutes to analyse two additional paintings. You may get help from other members of your group and help other members in your group while analysing the pictures. After the five minutes you are asked which artist painted which of the two additional paintings. Each correct answer will bring you 10 additional tokens. Details will be provided during the experiment.

After Part 1 has finished, the second part of the experiment starts.

\section{Instructions Part 2}

Part 2 of the experiment will consist of 15 periods, and in each period your group and the other group are competing for a prize in the following way: At the beginning of each period you will receive 100 tokens. Then you can use these tokens to buy lottery tickets for your group. Any token you invest gives one lottery ticket your group. Any token you do not invest in lottery tickets will remain in your private token account. Likewise, your group members can buy tickets for your group and the members of the other group can buy tickets for their group in exactly the same way.

As soon as everybody has chosen how many tickets to buy, a lottery will determine whether your 
group or the other group wins a prize of 300 tokens. All bought tickets are put in a "virtual" urn. One of the bought tickets will be randomly drawn as the winning ticket. Each ticket has the same chance to be drawn. Hence, the more tickets your group buys, the higher is your group?s chance of winning the prize. Examples: If your group and the other group buy the same amount of tickets then the chance of winning the prize is 50:50. This is also the case if none of the groups buy any tickets. If your group buys three times as many tickets as the other group, then also your group's chance is three times as high as that of the other group. If only one of the groups buys tickets then this group wins the prize with certainty.

If neither you nor the other players buy a ticket, then the prize is randomly allocated to one of the players with equal chances.

After the winning group is determined the prize of 300 tokens is equally shared between the members of the winning group and added to the private token accounts. As your group consists of 3 members, everyone in the winning group gets 100 tokens.

Earnings of a member of the winning group: 100 - bought lottery tickets +100

Earnings of a member of the losing group: 100 - bought lottery tickets

At the end of part 2 one of the 15 periods is randomly selected as the period that is paid out. You will receive information on how much you earned in each part of the experiment and which period was selected for the payoff in part 2 .

At the end of the experiment you are asked to fill out a questionnaire.

The experiment starts with a trial period in which you will be asked to fill in some questions in order to check your understanding of the experiment and to give you the opportunity to get acquainted with the setup. Tokens earned in this trial period will not be paid off. 
E.2 Experiment and Questionnaire Screens

Figure E.1: Screen 1

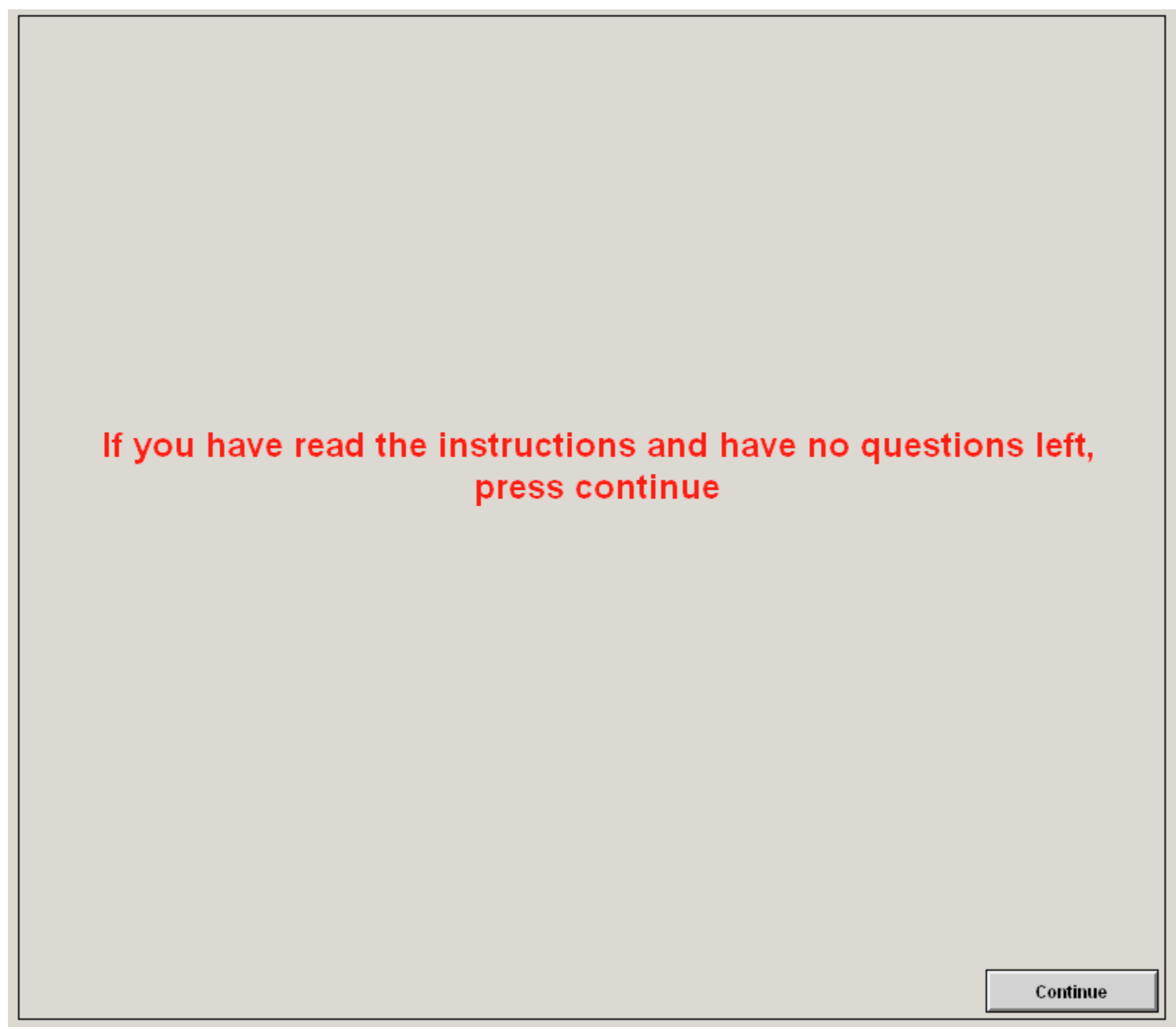


Figure E.2: Screen 2

Before we start with the first part of the experiment, there will be a trial period for the second part of the experiment.

All parameters in this trial period will be determined randomly. You will not yet be interacting with any other participant during this trial period.

Tokens gained during the trial period will not be transferred to your token account. After the trial period the experiment will start with part 1. 


\section{Figure E.3: Screen 3}

\begin{tabular}{|c|c|c|c|c|}
\hline \multicolumn{5}{|c|}{$\begin{array}{l}\text { This is a trial period. } \\
\text { Question } 1\end{array}$} \\
\hline & Initial Endowment & Lottery tickets bought & Earnings from Lottery & Total Earnings \\
\hline You & 100 & -- & -- & -- \\
\hline Other Member 1 & 100 & -- & -- & -- \\
\hline Other Member 2 & 100 & -- & -- & -- \\
\hline \multicolumn{5}{|c|}{$\begin{array}{l}\text { Imagine the situation that you bought } 50 \text { Lottery tickets. The other members of your group each buy the same amount. } \\
\text { How many Lottery tickets has your team bought in total? }\end{array}$} \\
\hline & & & & Ready \\
\hline
\end{tabular}


Figure E.4: Screen 4

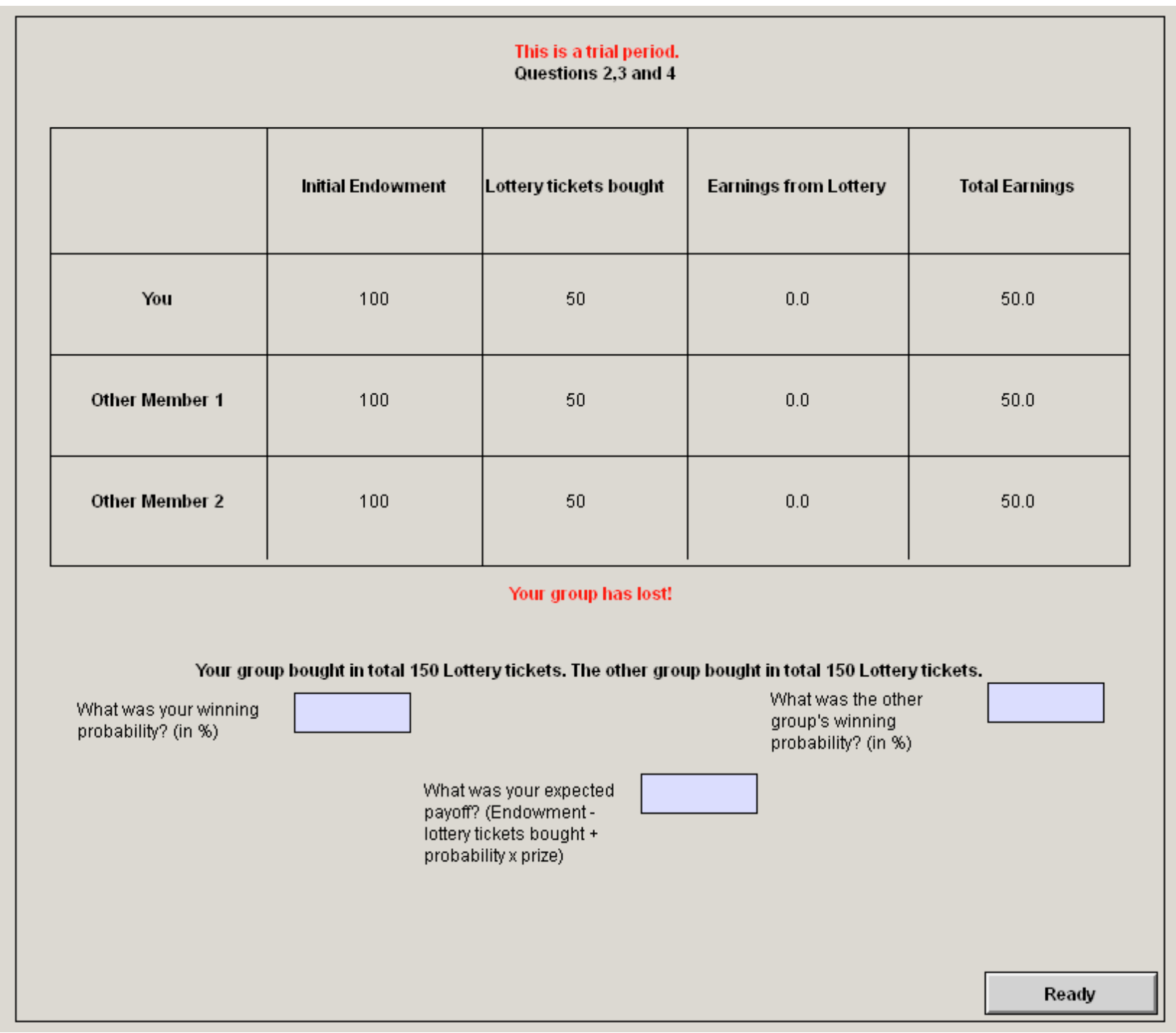




\section{Figure E.5: Screen 5}

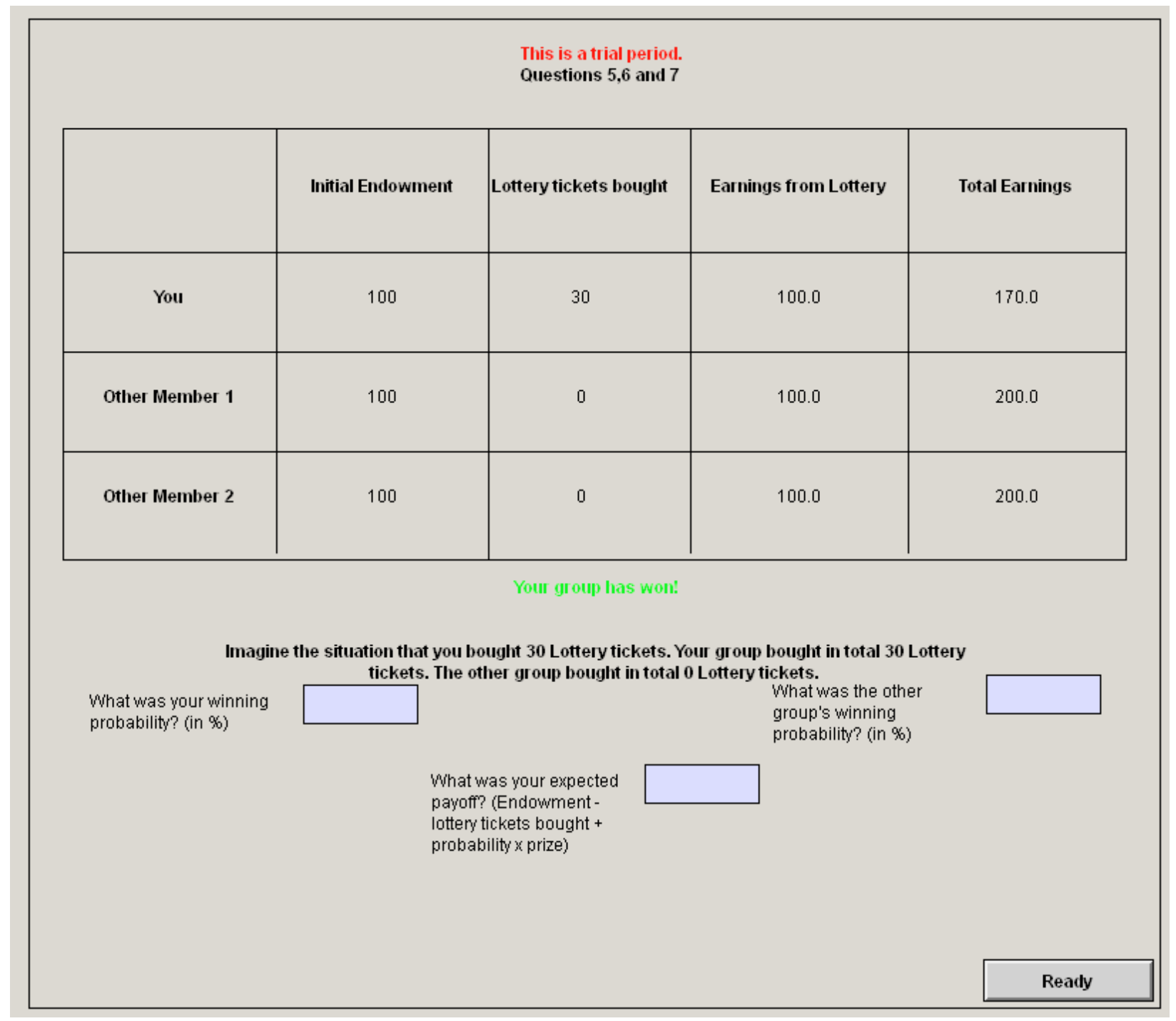


Figure E.6: Screen 6

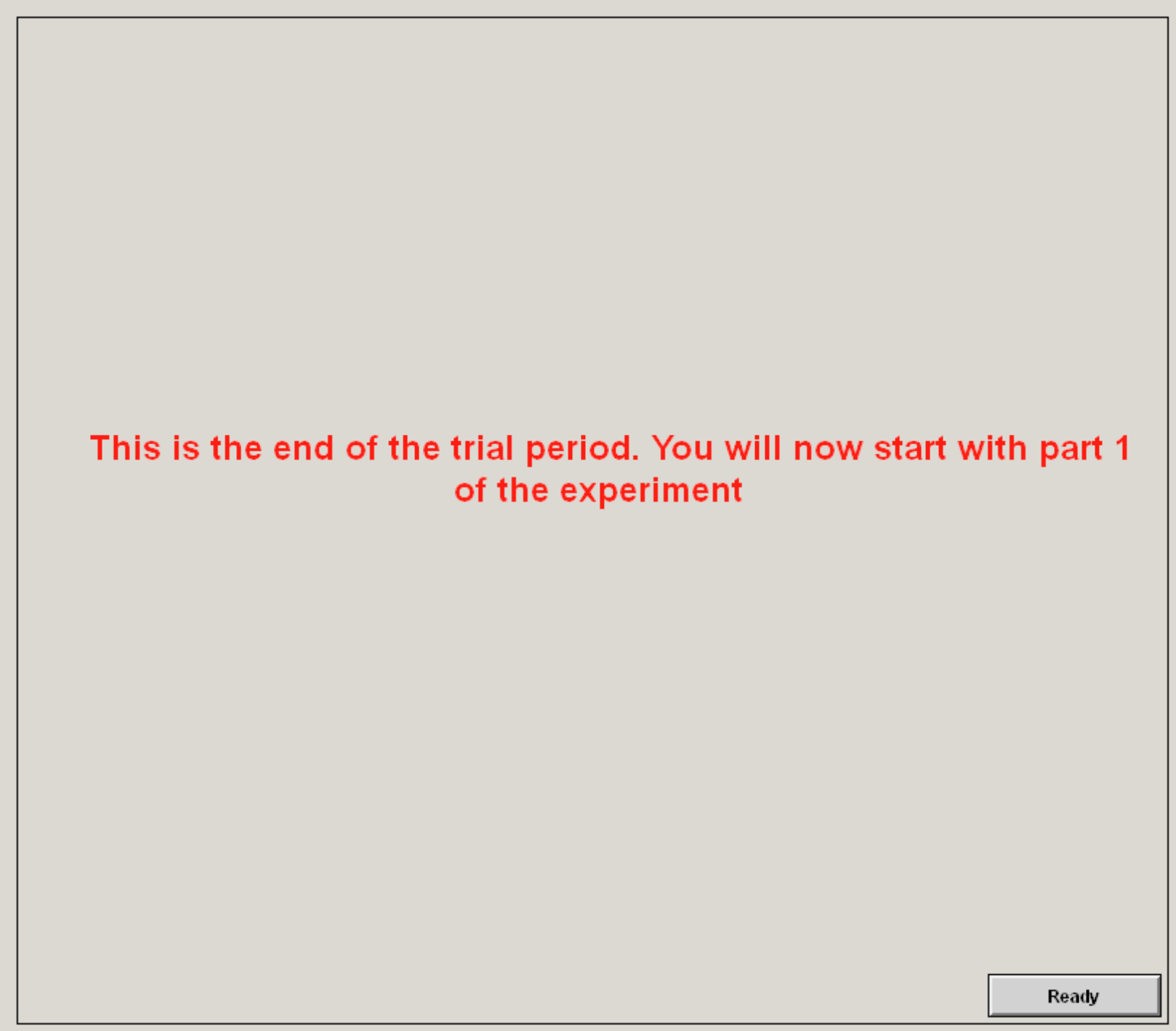


Figure E.7: Screen 7

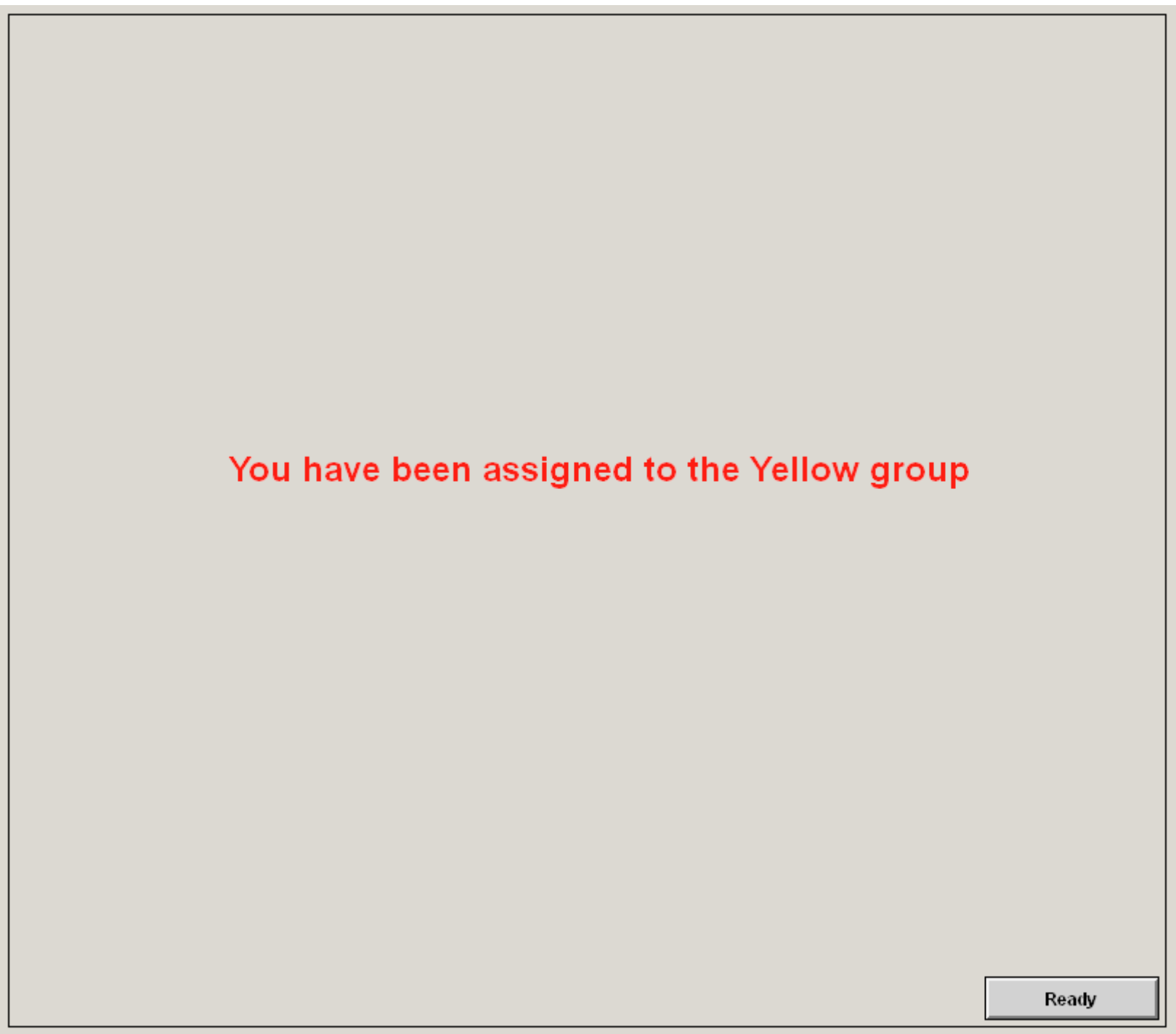


Figure E.8: Screen 8

\section{Part 1}

In this stage you view 5 pairs of paintings by Klee and Kandinsky. You will have 5 minutes to study these paintings. Then you will have another 5 minutes to analyse two other paintings. Each of these paintings was either painted by Klee or Kandinsky. You may get help from other members in your group and help other members in your own group through a group chat that will appear next to the pictures. You are free th post as many messages as you like. There are only two restrictions: You may not post messages which identity you (Gender, Age, etc.) and you may not use offensive or threatening language. Afterwards you are asked to correctly identify which artist painted which of the two pictures. Each correct answer will earn you 10 tokens. 
Figure E.9: Screen 9
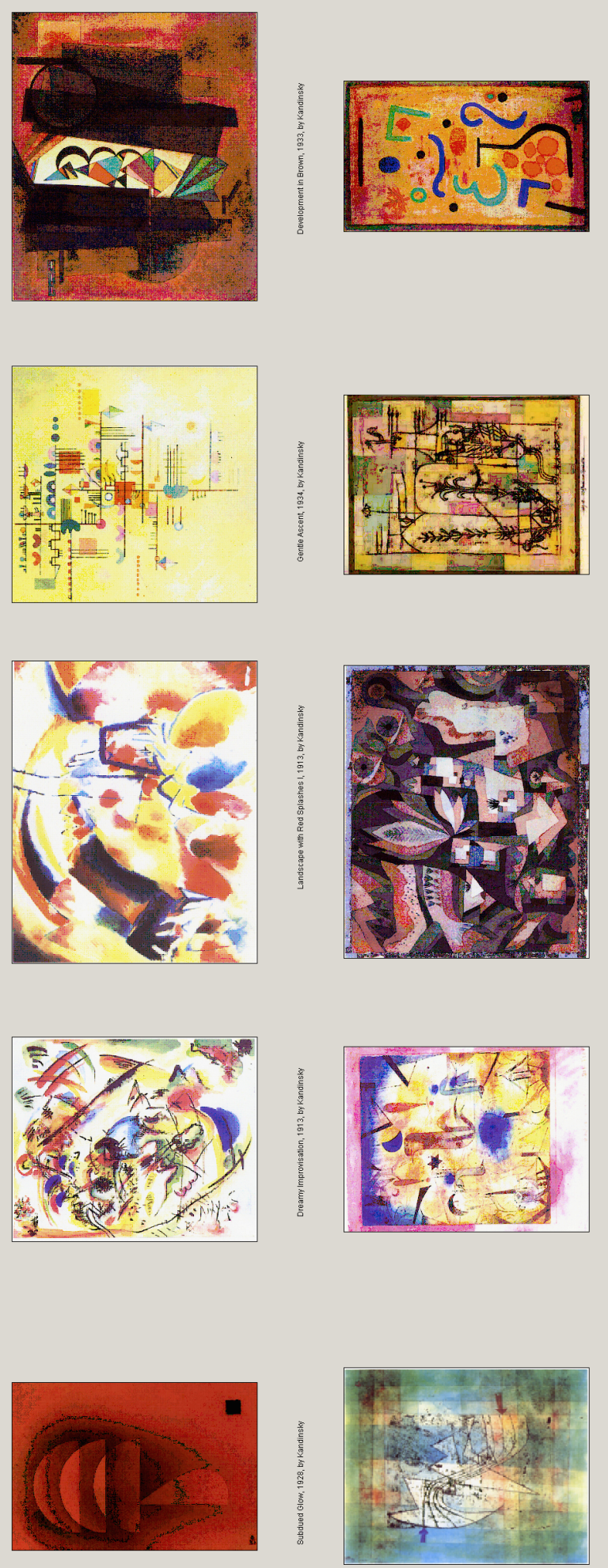
Figure E.10: Screen 10

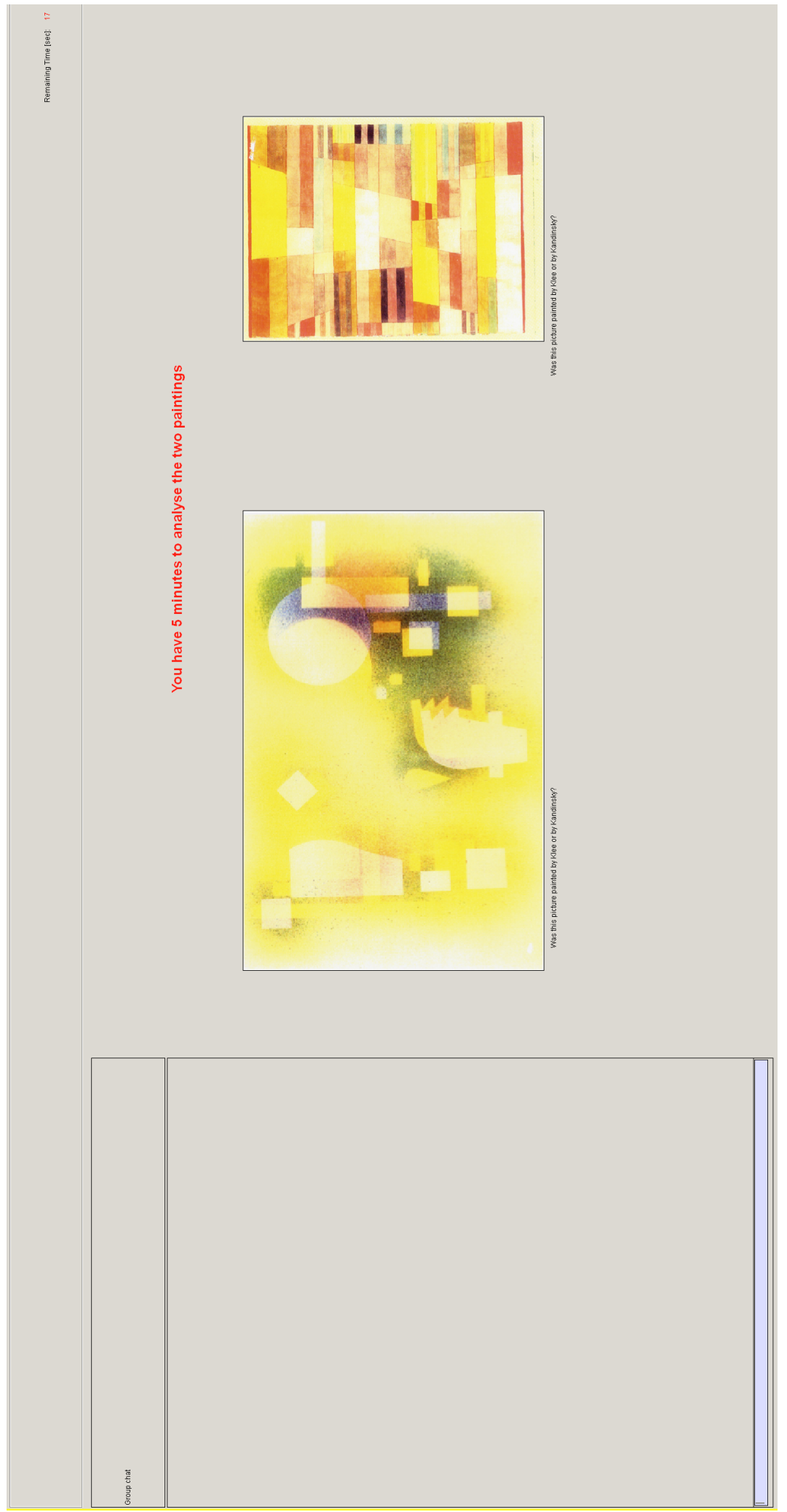


Figure E.11: Screen 11

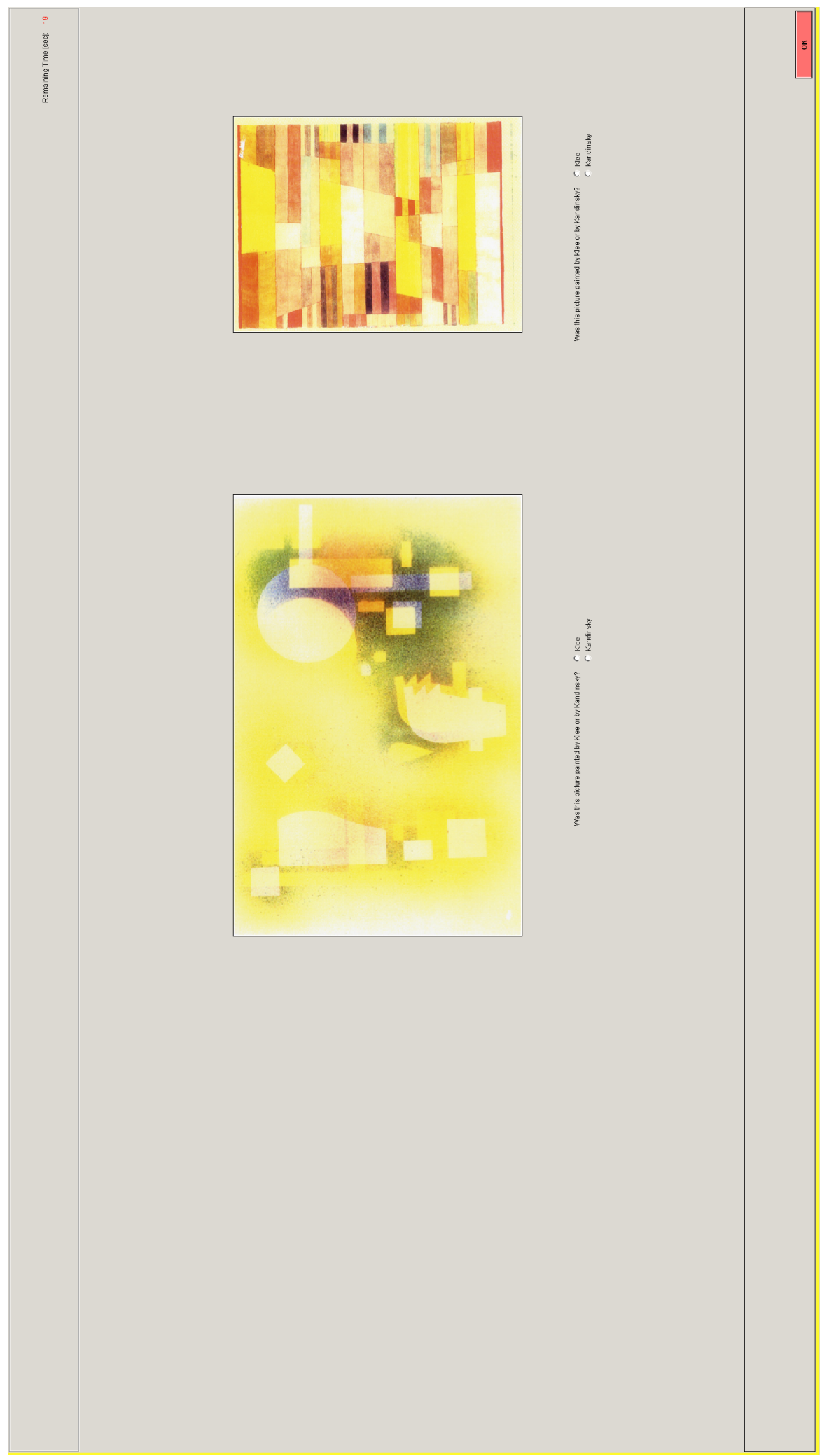


Figure E.12: Screen 12

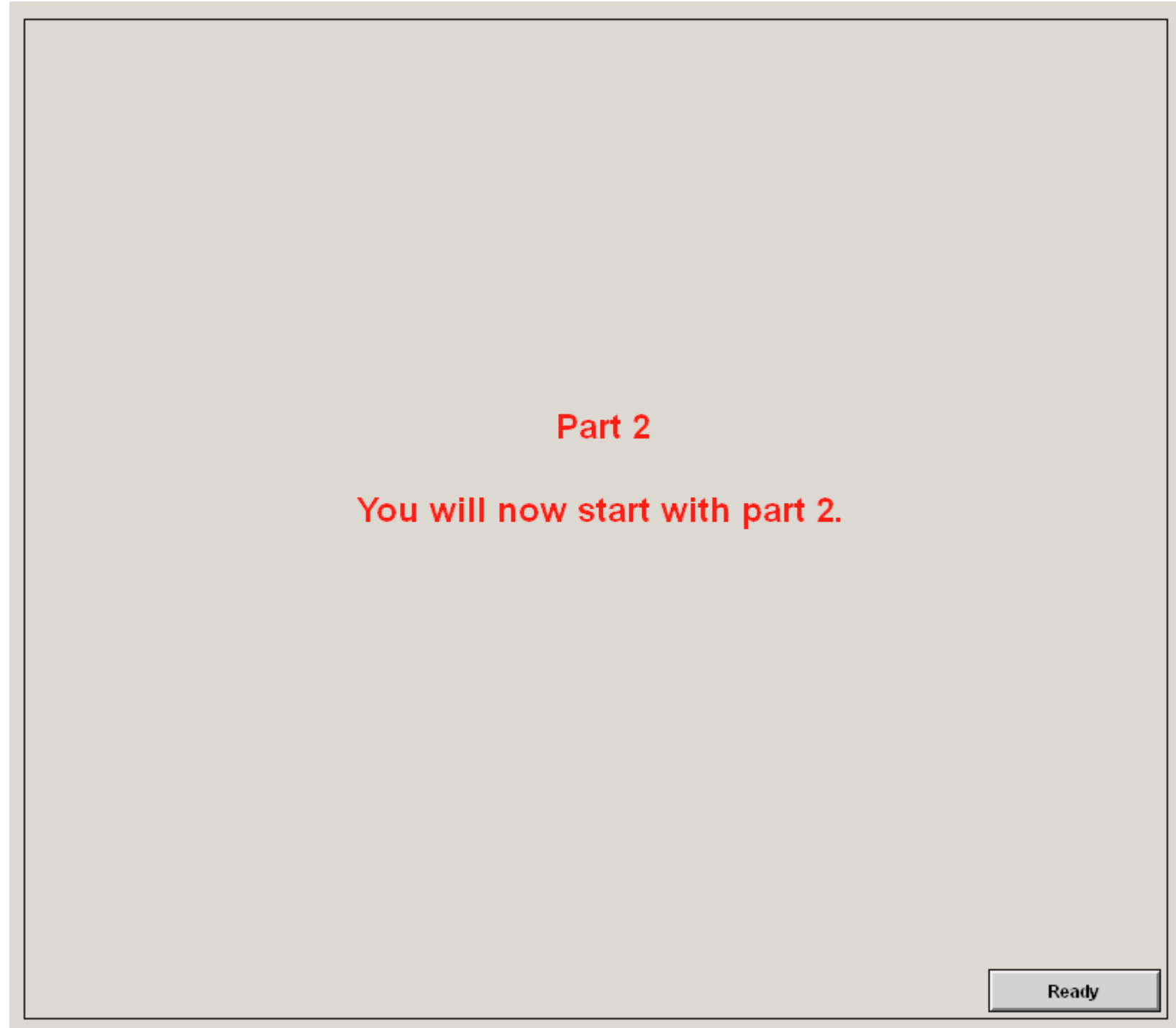


Figure E.13: Screen 13

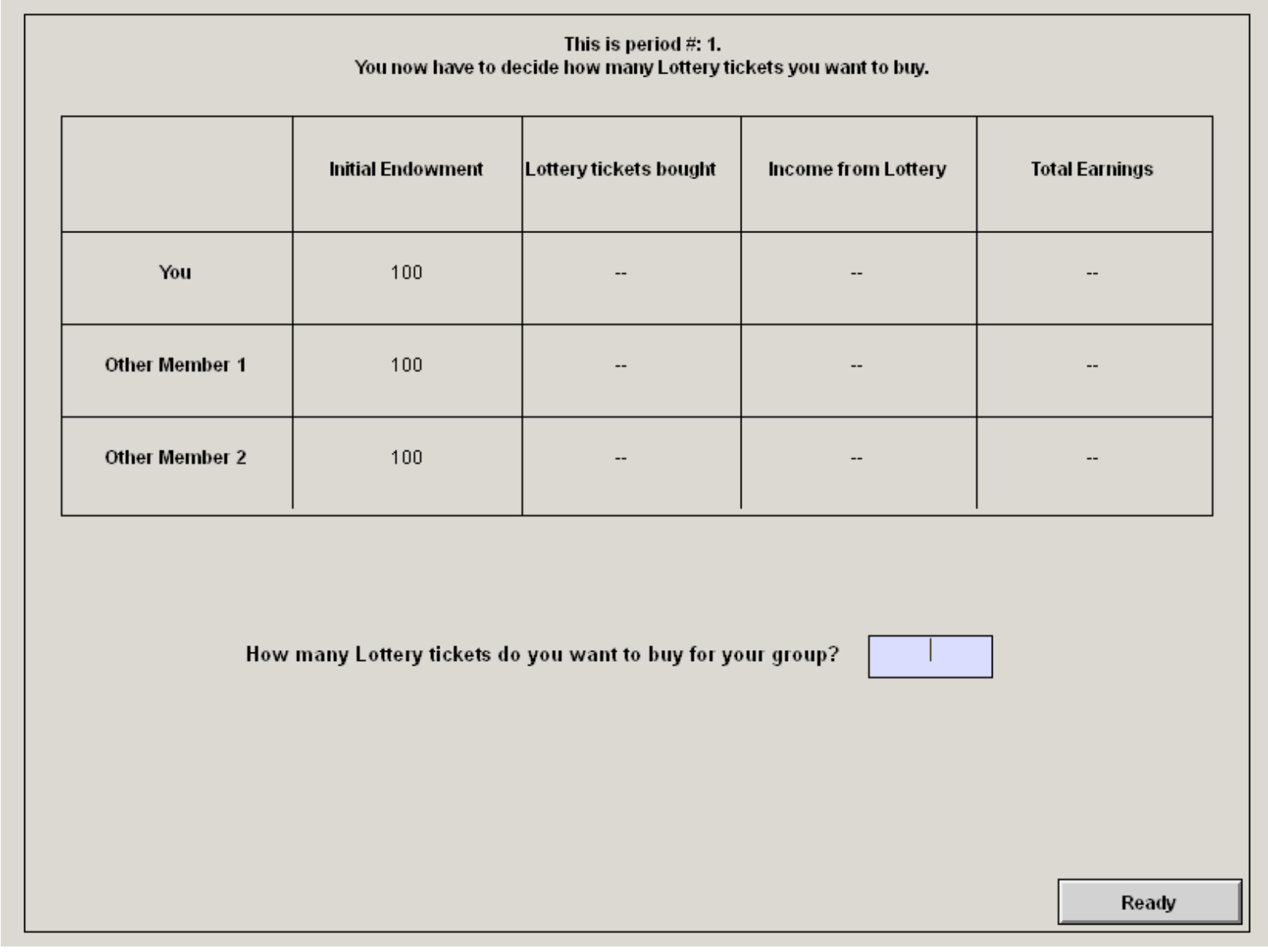


Figure E.14: Screen 14

\begin{tabular}{|c|c|c|c|c|}
\hline \multicolumn{5}{|c|}{$\begin{array}{l}\text { This is period \#: } 1 . \\
\text { Now you see if your group has won the price and how many Lottery tickets each of your group members bought. }\end{array}$} \\
\hline & Initial Endowment & Lottery tickets bought & Income from Lottery & Total Earnings \\
\hline You & 100 & 12 & 0.0 & 88.0 \\
\hline Other Member 1 & 100 & 44 & 0.0 & 56.0 \\
\hline Other Member 2 & 100 & 11 & 0.0 & 89.0 \\
\hline \multicolumn{5}{|c|}{ Your group has lost! } \\
\hline & & & & Ready \\
\hline
\end{tabular}


Figure E.15: Screen 15

Period 1 was randomly selected as the paying period.

Your Payoff in round 1 was 88

Total Payoff from the contest game in tokens:

88.0

Total Payoff from picture task in tokens:

20.0

Total earnings from the experiment in $€$

10.8 


\section{E.3 Summary Statistics and Frequency Tables}

Table E.1: Study Programme Frequencies

\begin{tabular}{lcccc}
\hline \hline \multirow{2}{*}{ Study Programme } & \multicolumn{2}{c}{ Control } & \multicolumn{2}{c}{ Social Identity } \\
& Freq. & Percent & Freq. & Percent \\
\hline International Business & 23 & 38.3 & 18 & 33.3 \\
Economics & 12 & 20.0 & 9 & 16.7 \\
Law & 7 & 11.7 & 8 & 14.8 \\
University College & 5 & 8.3 & 5 & 9.3 \\
European Studies & 3 & 5.0 & 1 & 1.9 \\
Psychology & 2 & 3.3 & 1 & 1.9 \\
Arts and culture & 0 & 0.0 & 2 & 3.7 \\
Econometrics & 1 & 1.7 & 0 & 0.0 \\
Other & 7 & 11.7 & 10 & 18.5 \\
\hline Total & 60 & 100.0 & 54 & 100.0 \\
\hline
\end{tabular}

Table E.2: Study Phase Frequencies

\begin{tabular}{lcccc}
\hline \hline \multirow{2}{*}{ Nationality } & \multicolumn{2}{c}{ Control } & \multicolumn{2}{c}{ Social Identity } \\
& Freq. & Percent & Freq. & Percent \\
\hline Bachelor & 47 & 78.3 & 46 & 85.2 \\
Master & 12 & 20.0 & 6 & 11.1 \\
Research Master & 0 & 0.0 & 1 & 1.1 \\
Other & 1 & 1.7 & 1 & 1.7 \\
\hline Total & 60 & 100.0 & 54 & 100.0
\end{tabular}


Table E.3: Nationality Frequencies

\begin{tabular}{lcccc}
\hline \hline \multirow{2}{*}{ Nationality } & \multicolumn{2}{c}{ Control } & \multicolumn{2}{c}{ Social Identity } \\
& Freq. & Percent & Freq. & Percent \\
\hline German & 18 & 30.0 & 22 & 40.7 \\
Dutch & 12 & 20.0 & 14 & 25.9 \\
Italian & 5 & 8.3 & 3 & 5.6 \\
British & 6 & 10.0 & 1 & 1.9 \\
Belgian & 2 & 3.3 & 4 & 7.4 \\
Polish & 0 & 0.0 & 3 & 5.6 \\
French & 2 & 3.3 & 0 & 0.0 \\
Chinese & 2 & 3.3 & 0 & 0.0 \\
Spanish & 0 & 0.0 & 1 & 1.9 \\
Other Europe & 4 & 6.7 & 1 & 1.9 \\
Other Asia & 3 & 5.0 & 1 & 1.9 \\
Other & 6 & 10.0 & 4 & 7.4 \\
\hline Total & 60 & 100.0 & 54 & 100.0 \\
\hline
\end{tabular}

Table E.4: Strategy Frequencies

\begin{tabular}{lcccc}
\hline \multicolumn{1}{c}{ Nationality } & \multicolumn{2}{c}{ Control } & \multicolumn{2}{c}{ Social Identity } \\
& Freq. & Percent & Freq. & Percent \\
\hline Maximizing own payoff & 38 & 45.8 & 34 & 42.0 \\
Maximizing group payoff & 31 & 37.3 & 32 & 39.5 \\
Earn more than group members & 5 & 6.0 & 5 & 6.2 \\
Earn more than everybody else & 3 & 3.6 & 4 & 4.9 \\
Maximize overall welfare & 4 & 4.8 & 2 & 2.5 \\
None of the above & 2 & 2.4 & 4 & 4.9 \\
\hline Total & $83^{*}$ & 100.0 & $81 *$ & 100.0 \\
*Multiple answers were possible & & & &
\end{tabular}


Table E.5: Comparison of Control Means between treatments

\begin{tabular}{|c|c|c|}
\hline Variable & $\begin{array}{l}\text { Control } \\
(\mathrm{N}=60)\end{array}$ & $\begin{array}{c}\text { Social identity } \\
\qquad(\mathrm{N}=54)\end{array}$ \\
\hline \multirow[t]{2}{*}{ Closeness to group } & 4.417 & 5.260 \\
\hline & $(2.451)$ & $(2.324)$ \\
\hline \multirow[t]{2}{*}{ Communication helpful } & & 4.981 \\
\hline & & $(2.764)$ \\
\hline \multirow[t]{2}{*}{ Picture known } & 2.533 & 2.722 \\
\hline & $(2.645)$ & $(2.587)$ \\
\hline \multirow[t]{2}{*}{ Right Answer Klee } & 0.650 & 0.648 \\
\hline & $(0.481)$ & $(0.482)$ \\
\hline \multirow[t]{2}{*}{ Right Answer Kandinsky } & 0.267 & 0.278 \\
\hline & $(0.481)$ & $(0.452)$ \\
\hline \multirow[t]{2}{*}{ Number of correct answers } & 0.917 & 0.926 \\
\hline & $(0.334)$ & $(0.428)$ \\
\hline \multirow[t]{2}{*}{ Number of chat messages sent } & & 6.759 \\
\hline & & $(4.463)$ \\
\hline \multirow[t]{2}{*}{ Risk general } & 5.150 & 5.704 \\
\hline & $(1.998)$ & $(1.899)$ \\
\hline \multirow[t]{2}{*}{ Gender } & 0.633 & 0.611 \\
\hline & $(0.486)$ & $(0.492)$ \\
\hline \multirow[t]{2}{*}{ Age } & 21.717 & 21.111 \\
\hline & $(2.799)$ & $(1.7555)$ \\
\hline \multirow[t]{2}{*}{ Siblings } & 1.550 & 1.648 \\
\hline & $(1.096)$ & $(1.102)$ \\
\hline \multirow[t]{2}{*}{ Team sports } & 0.700 & 0.611 \\
\hline & $(0.462)$ & $(0.492)$ \\
\hline
\end{tabular}

Standard Deviations in parentheses 